\title{
Immunogenomics reveal molecular circuits of diclofenac induced liver injury in mice
}

\author{
Eun-Hee Lee ${ }^{1}$, Jung-Hwa Oh ${ }^{1,2}$, Saravanakumar Selvaraj ${ }^{3}$, Se-Myo Park ${ }^{1}$, Mi-Sun \\ Choi $^{1}$, Reinhard Spanel ${ }^{3,4}$, Seokjoo Yoon ${ }^{1,2, *}$, Jürgen Borlak ${ }^{3, *}$ \\ ${ }^{1}$ Department of Predictive Toxicology, Korea Institute of Toxicology, Daejeon, 305-343, Republic of Korea \\ ${ }^{2}$ Department of Human and Environmental Toxicology, School of Engineering, Korea University of Science and Technology, \\ Daejeon, 305-343, Republic of Korea \\ ${ }^{3}$ Centre for Pharmacology and Toxicology, Hannover Medical School, 30625 Hannover, Germany \\ ${ }^{4}$ Institute for Clinical Pathology, 41747 Viersen, Germany \\ *These authors contributed equally to this work
}

Correspondence to: Jürgen Borlak, e-mail: borlak.juergen@mh-hannover.de

Keywords: diclofenac, NSAID, gene expression profiling, inflammation, immune response

Received: September 25, 2015

Accepted: January 12, 2016

Published: February 25, 2016

ABSTRACT

Diclofenac is a non-steroidal anti-inflammatory drug and its use can be associated with severe adverse reactions, notably myocardial infarction, stroke and drug-induced liver injury (DILI). In pursue of immune-mediated DILI mechanisms an immunogenomic study was carried out. Diclofenac treatment of mice at $30 \mathrm{mg} / \mathrm{kg}$ for 3 days caused significant serum ALT and AST elevations, hepatomegaly and degenerative changes including hepatic glycogen depletion, hydropic swelling, cholesterolosis and eosinophilic hepatocytes with one animal presenting subsegmental infarction due to portal vein thrombosis. Furthermore, portal/periportal induction of the rate limiting enzyme in ammonia detoxification, i.e. carbamoyl phosphate synthetase 1 was observed. The performed microarray studies informed on $>600$ differential expressed genes of which 35, 37 and 50 coded for inflammation, 51, 44 and 61 for immune and 116, 129 and 169 for stress response, respectively after single and repeated dosing for 3 and 14 days. Bioinformatic analysis defined molecular circuits of hepatic inflammation with the growth hormone (Ghr) - and leptin receptor, the protein-tyrosine-phosphatase, selectin and the suppressor-ofcytokine-signaling (Socs) to function as key nodes in gene regulatory networks. Western blotting confirmed induction of fibronectin and M-CSF to hallmark tissue repair and differentiation of monocytes and macrophages. Transcript expression of the macrophage receptor with collagenous structure increased $>7$-fold and immunohistochemistry of CD68 evidenced activation of tissue-resident macrophages. Importantly, diclofenac treatment prompted strong expression of phosphorylated Stat3 amongst individual animals and the associated 8- and 4-fold Soc3 and Il-6 induction reinforced $\mathbf{G h r}$ degradation as evidenced by immunoblotting. Moreover, immunohistochemistry confirmed regulation of master regulatory proteins of diclofenac treated mice to suggest complex pro-and anti-inflammatory reactions in immune-mediated hepatic injury. The findings encourage translational research.

\section{BACKGROUND}

Diclofenac is a nonsteroidal anti-inflammatory drug (NSAID) and an antipyretic commonly used in the treatment of inflammatory disorders, rheumatoid arthritis and chronic pain associated with cancer. Repeatedly it was shown that diclofenac use can be associated with drug induced liver injury [1]. The mechanism by which diclofenac causes liver injury remains incompletely understood. However, some clinical and experimental data have been put forward for an improved understanding of hepatotoxicity [2]. 
Specially, diclofenac is extensively metabolized to $4^{\prime}-\mathrm{OH}$ and $5^{\prime}-\mathrm{OH}$ diclofenac by the Cyp2c9 and Cyp3a4 monooxygenase system and may also involve increased production of reactive metabolites, most notable diclofenac-2,5- and 1,4-quinone imines. Reactive metabolites can be a leading cause of liver injury, particularly if not sufficiently detoxified via the glutathione redox and conjugation system. Notwithstanding secondary quinone imine metabolites derived from 5-OH and 4'-OH diclofenac glutathione conjugates may be eliminated via biliary excretion especially when bile salt homeostasis is altered. Diclofenac is also metabolized to $4^{\prime}-\mathrm{OH}$ diclofenac (DCF) acyl glucuronide by the combined activity of CYP2C8 and UGT2B7 in humans and Ugt2b1 in rats. The reactive metabolites are electrophilic and protein-diclofenac adducts have been identified [3]. Additionally, diclofenac acyl glucuronides may accumulate in liver and blood plasma due to saturated drug transport into the biliary canaliculi, and polymorphisms in some ATP-binding cassette transporters (Mrp2, Mrp3 and $B c r p 1$ ) are associated with cholestatic liver disease as reported for this drug [4].

In vitro, diclofenac induced apoptosis through mitochondrial dysfunction and oxidative stress in rat and human hepatocytes and hepatoma cell lines [5] and Bax/Bak-mediated mitochondrial outer membrane permeabilization (MOMP) was shown to be a major mechanism of diclofenac-induced hepatotoxicity in a human hepatoma cell line [6, 7]. Moreover, diclofenac inhibited nuclear factor-kappa $\mathrm{B}(N F-\kappa \mathrm{B})$ activation induced by tumour necrosis factor $\alpha(T N F \alpha)$, to result in apoptosis in human and mouse hepatoma cell lines [8]. In rats, a non-hepatotoxic dose of diclofenac co-administered with small amounts of lipopolysaccharide (LPS) caused hepatotoxicity and modest inflammation induced by LPS sensitized hepatocytes to a non-toxic dose of diclofenac [9]. In this regard a $\mathrm{T}$ helper 17 cell (Th17)-related immune response was reported in diclofenac-induced acute liver injury in mice [10].

In patient serum samples several protein-adducts of diclofenac and antibodies to diclofenac metabolites were identified. Furthermore, polymorphisms in the gene coding for $I l-10, I l-4$ and $I l-4 r$ were associated with diclofenac hepatotoxicity and its outcome [11]. According to clinical research, cholestasis and transient circulating autoantibodies are seen in patients who suffered from acute and chronic hepatitis due to diclofenac [12] and with some patients an autoimmune response was seen after cessation of diclofenac treatment [2, 13], [http://livertox. nlm.nih.gov/Diclofenac.htm]. All these studies suggest an immune mechanism as part of the pathogenesis of diclofenac's idiosyncratic toxicity.

Here we hypothesized for diclofenac a mechanism of hepatotoxicity involving inflammatory reactions. Thus our research focused on an evaluation of acute and repeated treatment responses for up to 14 days. We were particularly interested in identifying molecular circuits of inflammatory response genes and employed whole genome microarrays, qRT-PCR, immunohistochemistry as well as Western blotting to evidence regulation of key molecules in affected livers.

\section{RESULTS}

\section{Serum markers of liver injury and histopathology findings}

The serum markers AST, ALT, ALP and total bilirubin (TBIL) were studied after single and repeated treatment, i.e. days 1, 3 and 14. A statistically significant increase in AST and ALT and a reduction in ALP activities (Figure 1) were observed after i.p. administration of diclofenac at $30 \mathrm{mg} / \mathrm{kg}$; however, bilirubin did not differ when control and treatment groups were compared. There was significant variability amongst individual animals to suggest difference in response with some animals being less able to adapt to this treatment regime as was observed after repeated treatment for 14 days (see Figure S1 for individual blood biochemistry data).

To explore dose dependent changes in serum markers of liver injury mice were also treated at $150 \mathrm{mg} / \mathrm{kg}$ for up to 3 days. However, a dose dependent change in AST, ALT and ALP activities could not be established as measurements were highly variable amongst individual animals. Moreover, at this dose acute liver failure/death was observed in two out of four animals and additional treatment of two mice caused fatal liver injury in one and acute liver failure in another one. Thus the study was terminated after $48 \mathrm{~h}$ of diclofenac treatment.

Diclofenac treatment caused a significant increase in the liver to body weight ratio (Table 1) and histopathology revealed dose dependent glycogen depletion after single and repeated treatment for up to 3 days (Figure 2). Conversely, hepatic glycogen was only modestly changed after repeated dosing for 14 days (image not shown) to possibly suggest adaptation to diclofenac treatment. Individual animals differed in their responses, nonetheless the Hematoxylin-eosin stain revealed hydropic swelling of heptocytes (Figure 2, Panel A). With some animals repeated diclofenac treatment induced hepatic cholesterolosis ("foamy cytoplasm") and one animal presented infarct necrosis as a result of portal vein thrombosis (Figure 2, Panel D). Although serum bilirubin laboratory values were within normal range and alkaline phosphatase activity was significantly reduced (Figure 1) the bile ducts in some of the treated animals were dilatated and congested with bile to indicate early signs of bile duct obstruction (Figure 2, panel C, PAS stain illustrating a dilatated and bile fluid filled canaliculi).

A range of immunohistochemistry studies were performed with CD31 evidencing sinusoidal endothelial cells to be intact (not shown), however hepatic sinusoids 
appeared partially widened. Likewise, the increased staining for CD68 (Figure 3A) marked activated Kupffer cells and appeared to be co-stimulated by the enhanced secretion of the cytokine macrophage colony-stimulating factor (M-CSF) as observed for the centrolobular regions (Figure 3B). Equally, the pronounced sinusoidal and occasionally strong hepatic expression of the acute phase protein lipopolysaccharide binding protein (LBP) reinforces the notion of Kupffer cell activation (Figure 4). Note, LBP is bound by CD14 and transcript expression of this pattern recognition receptor was $>30$-fold induced (see Table S9). Further evidence for proliferation of sinusoidal resident antigen-presenting cells was obtained by examining Ki67. An increase in Ki67 positive cells was observed (Figure 5) and it is well established that activated Kupffer cells release cytokines, chemokines, reactive oxygen species and other mediators of inflammation. As the activation of resident macrophages was not confined to regions of harmed hepatocytes diclofenac treatment induced a more general response by augmenting drug induced hepatitis. Alike, the significant regulation of the T-cell protein tyrosine phosphatase (Tc-PTP; Figure 6) is an important finding. Tc-PTP is a key player of the immune system and a negative regulator of Colony-Stimulating Factor 1 (CSF-1) signalling and macrophage differentiation. Note, CSF-1 was significantly repressed in transcript expression by nearly $40 \%$ in livers of diclofenac treated mice (see Table S2).

A
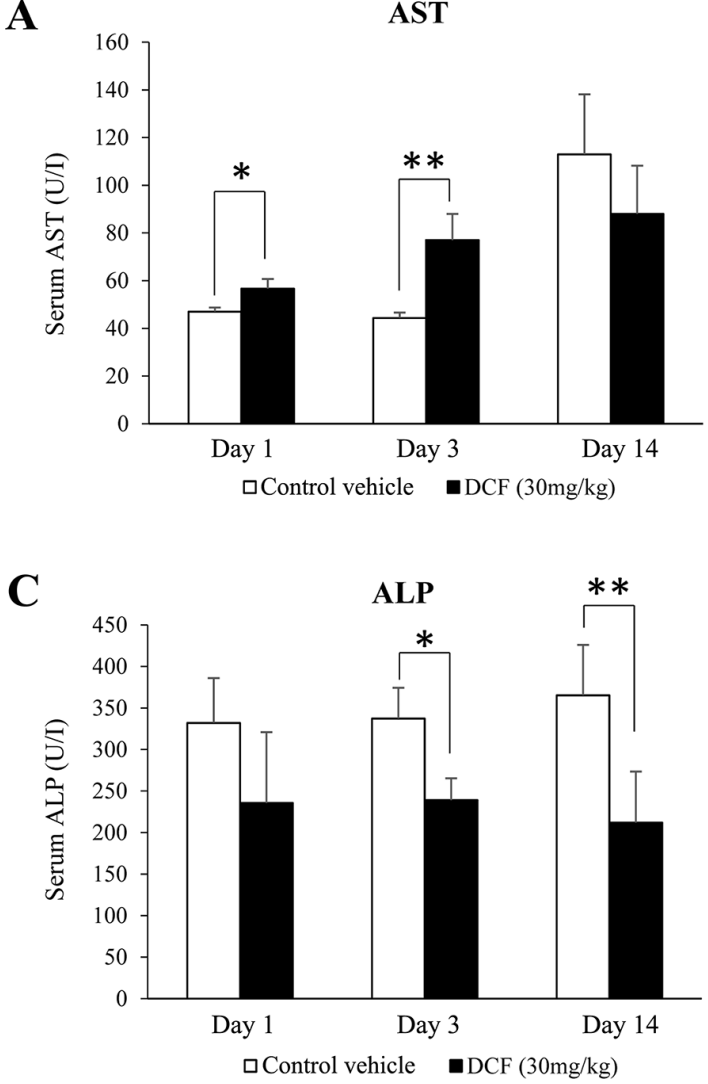

Moreover, enhanced expression of fibronectin, i.e. a matrix glycoprotein known to influence hepatic survival was strongly upregulated particularly at the $150 \mathrm{mg} / \mathrm{kg}$ dose to signify tissue repair (Figure 7, Panel D). Besides, we investigated regulation of the growth hormone receptor (Ghr, Figure 8) and found its expression to be significantly increased in the sinusoids especially of periportal and intermediate regions localised hepatocytes after single treatment (day 1), however Ghr staining was markedly reduced after repeated treatment for 3 days. Importantly, growth hormone signals through Ghr and is known to play a decisive role in liver regeneration. Moreover, diclofenac treatment induced enhanced sinusoidal expression of the leptin receptor (Figure 9); its infrequently increased expression by harmed hepatocytes was also observed. In addition, we investigated the expression of Hep Par 1 (Figure S2) and noted strong cytoplasmic staining of hepatocytes in diclofenac treated animals, however the centrolobular regions were spared. It was demonstrated that Hep Par 1 recognizes the urea cycle rate limiting enzyme carbamoylphosphate synthetase 1 . Hence, we evidence ammonia detoxification and observed strong focal staining of hepatocytes surrounding the portal tracts (see day 3, $30 \mathrm{mg} / \mathrm{kg}$ ). Enhanced expression of the antigen was also observed with disperse hepatocytes as seen at the $150 \mathrm{mg}$ treatment dose (Figure S2, Panel C). Finally, we examined the possibility of liver architectural changes

B

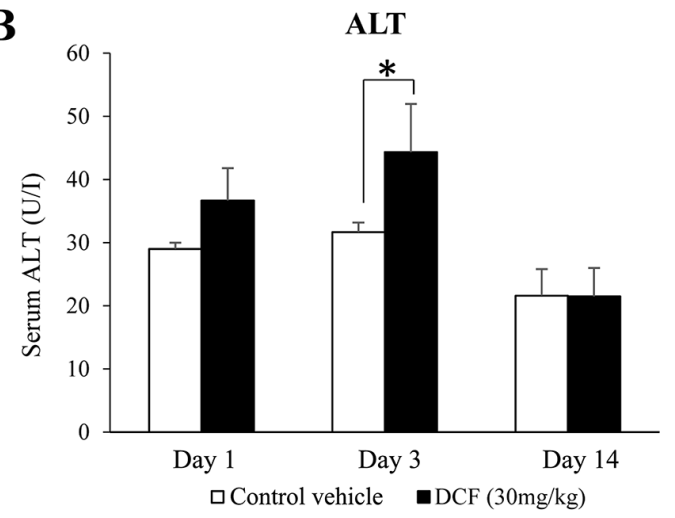

D

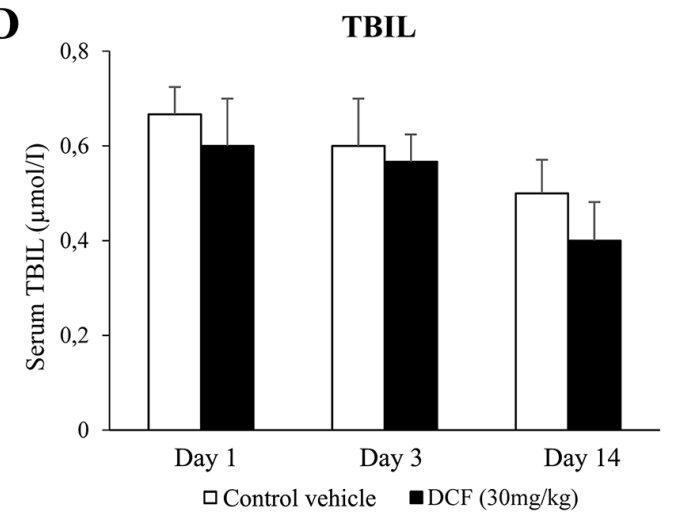

Figure 1: Serum AST, ALT, ALP and TBIL levels in diclofenac-administered mice. Diclofenac (30 mg/kg, i.p.) was given to mice for day 1,3 and 14 . Result are means $\pm \operatorname{SD}(n=3 ; * P<0.05, * * P<0.01)$. 
Table 1: Body and liver weights after diclofenac treatment

\begin{tabular}{|c|c|c|c|c|c|}
\hline \multirow[b]{2}{*}{ Duration } & \multirow[b]{2}{*}{ Dosage } & \multicolumn{2}{|c|}{ Body weight (g) } & \multicolumn{2}{|c|}{ Liver weight (g) } \\
\hline & & $\begin{array}{c}\text { Before } \\
\text { administration }\end{array}$ & $\begin{array}{c}\text { After } \\
\text { administration }\end{array}$ & Absolute weight (g) & Relative ratio (\%) \\
\hline \multirow{2}{*}{ Day 1} & Vehicle & $22.86 \pm 1.64$ & $23.63 \pm 1.24$ & $1.13 \pm 0.03$ & $4.77 \pm 0.18(100)$ \\
\hline & $30 \mathrm{mg} / \mathrm{kg}$ & $21.16 \pm 1.11$ & $20.90 \pm 0.14$ & $1.08 \pm 0.03$ & $5.14 \pm 0.12_{\mathrm{a}}(108)$ \\
\hline \multirow{2}{*}{ Day 3} & Vehicle & $20.68 \pm 0.86$ & $22.48 \pm 0.43_{b}$ & $1.13 \pm 0.03$ & $5.02 \pm 0.08(100)$ \\
\hline & $30 \mathrm{mg} / \mathrm{kg}$ & $22.02 \pm 1.02$ & $22.84 \pm 0.54$ & $1.21 \pm 0.03_{\mathrm{a}}$ & $5.31 \pm 0.25(106)$ \\
\hline \multirow{2}{*}{ Day 14} & Vehicle & $24.62 \pm 1.03$ & $21.01 \pm 1.22$ & $0.92 \pm 0.13$ & $4.41 \pm 0.72(100)$ \\
\hline & $30 \mathrm{mg} / \mathrm{kg}$ & $24.80 \pm 0.83$ & $20.43 \pm 0.84_{c}$ & $1.05 \pm 0.06$ & $5.14 \pm 0.18(117)$ \\
\hline
\end{tabular}

Values represent the means \pm standard deviation (SD). The relative organ weight was calculated using the ratio of liver weight to body weight and is represented as a percentage of the total body weight.

$P$-values were calculated using the Student's $t$-test and significance is defined by

${ }_{2} P<0.05 ; v s$. corresponding control vehicle.

a) $P<0.05 ;$ vs. corresponding before administration;

${ }_{\text {c) }} P<0.01$; vs. corresponding before administration.

in animals treated repeatedly for 14 days. By employing the Elastica van Gieson and the Gomori silver stain no evidence was obtained for early signs of fibrosis or enhanced deposition of extra cellular matrix into the sinusoids.

\section{Genomic response of the liver to diclofenac treatment}

RNA was extracted from livers of vehicle- and diclofenac $(30 \mathrm{mg} / \mathrm{kg})$-treated mice after single, i.e. $24 \mathrm{~h}$ and repeated dosing for $72 \mathrm{~h}$ and 14 days. Because of the sudden death of two animals at the $150 \mathrm{mg} / \mathrm{kg}$ dose the livers from high dose animals were not used for the microarray experiments. Gene expression profiling of RNA samples was performed with the Affymetrix GeneChip System. Initially, the data were analysed with the GenPlex software version 3.0 [http://genplex.co.kr] and a total of 295 and 467 significantly regulated genes at $>1.5$-fold change and statistical significance testing (Welch's $t$-test, $p<0.05$ ) were determined after single and repeated treatment for 3-days. Additionally, the microarray data were analysed with the GeneXplain software version 3.0 [http://platform.genexplain.com/bioumlweb]. Here a total of 471 (293 up- and 178 down-) and 564 (353 up- and 211 down-) DEGs were determined after single and repeated treatment for 3 days, of which 132 genes were (89 up- and 43 down-) regulated in common amongst both datasets (see Figure 10A.1 and Table 2A). Besides, the 14 day repeated diclofenac treatment revealed 666 (455 up- and 211 down-) differentially expressed genes (DEGs) of which 74 were common when data from day 1, 3 and 14 were compared (Figure 10A.2 and Table 2B). Next, a heat map was generated using the average-linkage hierarchical clustering and the Euclidean distance algorithm. As shown in Figure 10B several genes were regulated in common coding for inflammatory, immune, stress and acute-phase response. Both of the softwares employed, i.e. GeneXplain and GenPlex informed on the significant regulation of the inflammatory, immune and stress response genes (Table S2), even though the total number of DEGs differed when the Welch and/or hypergeometric statistical test were applied.

\section{Regulation of transporters and drug metabolism genes}

As diclofenac is extensively metabolized we initially assessed the regulation of genes coding for CYP enzymes and transporters. The microarray study revealed Cyp26a1, Cyp2a4, Cyp2a5, Cyp3a13, Cyp2b9, Cyp2c40 and Cyp2c55 to be significantly regulated after single treatment. Likewise, repeated treatment for up to 14 days caused significant regulations of Cyp $7 a 1$, Cyp39A1, Cyp2c39, Cyp3a44 and Cyp3a13. Note, Cyp7a1 catalyses the hydroxylation of cholesterol during bile acid synthesis and was significantly up-regulated after repeated treatment; nonetheless genes coding for transporters were more frequently changed than those involved in drug metabolism and included major mitochondrial solute carriers (Table S3).

\section{Top bio-functions of genes influenced by diclofenac treatment}

The GeneXplain and GenPlex software defined the top biological processes of DEGs with significant $p$-value (Tables S4-S6). Using the Ingenuity Pathway Analysis software and by applying the Fisher's exact test a functional enrichment analysis was performed and 
the statistically significant DEGs were categorized into diseases and disorders, molecular and cellular functions, physiological system, development and function (see Tables S7 and S8). Significantly enriched ontology terms were mainly associated with inflammatory response, gastrointestinal disease, organism injury/ abnormalities and renal/urological disease after single treatment. Similarly, the genomic responses after repeated treatment involved inflammation, infectious and inflammatory disease as well as respiratory and hematological disorders with several of the inflammatory response genes being equally regulated after single and
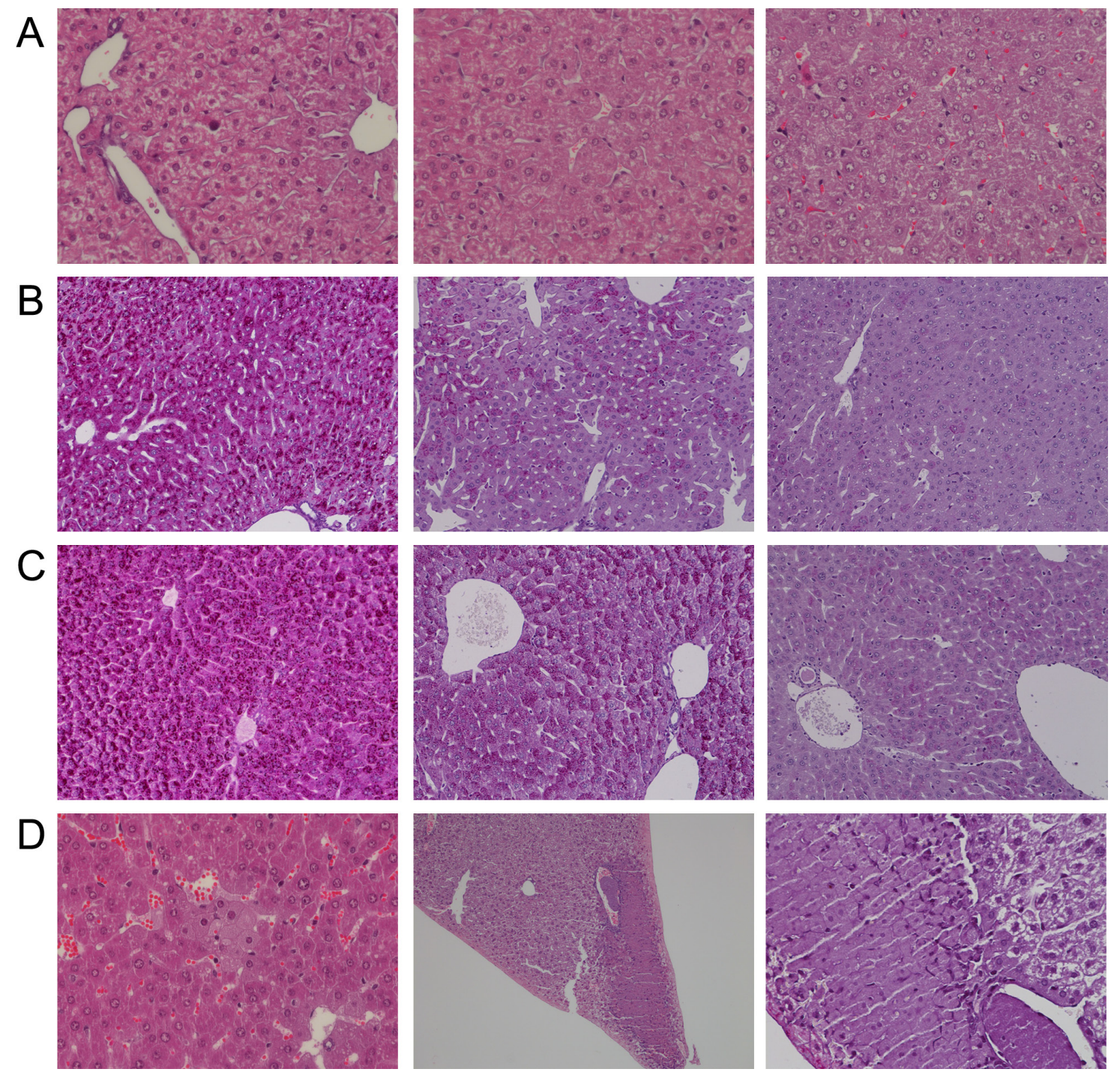

Figure 2: Hematoxylin-eosin and PAS staining of liver sections of Diclofenac treated mice. Depicted are representative examples of vehicle control and diclofenac treated animals. (A) from the left to the right: H \& E stain of vehicle control, single (day 1, $30 \mathrm{mg} / \mathrm{kg}$ ) and repeated diclofenac treatment of mice (day $3,150 \mathrm{mg} / \mathrm{kg}$ ). With control animals the nuclei of hepatocytes appeared quiescent and the cytoplasm of hepatocytes is rich in glycogen ("cloudy"). With treated animals hydropic cytoplasmic swelling of hepatocytes and occasionally eosinophilic hepatocytes are observed (upper left corner, $150 \mathrm{mg} / \mathrm{kg}$ animal). The nuclei are activated and the nucleoli are enlarged. The degenerative changes are more pronounced at the higher dose (magnification 200x). (B) from the left to the right: PAS staining of vehicle control and single (day 1) diclofenac treatment at 30 and $150 \mathrm{mg} / \mathrm{kg}$. When compared to vehicle controls a significant reduction in the intense PAS staining of hepatocytes was observed to suggest hepatic depletion of glycogen as a result of diclofenac treatment (magnification 100x). (C) from the left to the right: PAS staining of vehicle control and after repeated diclofenac treatment (day 3 ) at $30 \mathrm{and} 150 \mathrm{mg} / \mathrm{kg}$. Similar to Panel B and when compared to controls the PAS stain revealed significant depletion of the hepatic glycogen content. Note, the dilatated bile duct in the image given on the right possibly indicates early signs of bile duct obstruction (magnification 100x). (D) from the left to the right: H \& E stain of repeated diclofenac treatment for 2 days at $150 \mathrm{mg} / \mathrm{kg}$. An example of foamy hepatocytes ("hepatic cholesterolosis") is given. The second image of panel D (x70 magnification) depicts infarct necrosis observed with an animal after repeated dosing at $30 \mathrm{mg} / \mathrm{kg}$ for 3 days. The image on the right is a Diastase-PAS stain and a higher magnification of the infarct necrosis and the fresh thrombosis of the adjacent portal vein (magnification 200x). 


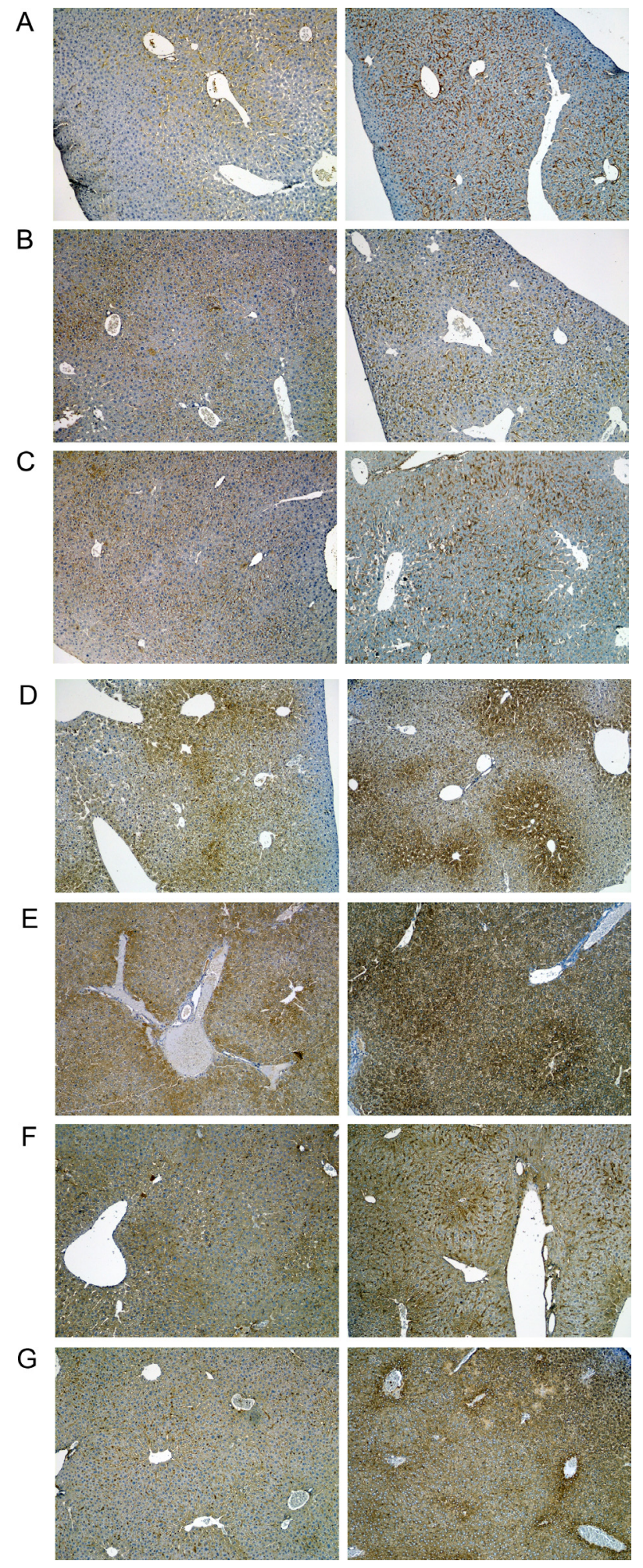

Figure 3: Immunohistochemistry of CD68 in livers of control and diclofenac treated mice. (A) from the left to the right: Control and single dose $30 \mathrm{mg} / \mathrm{kg}$ diclofenac (day 1). (B) from the left to the right: Control and repeated dose $30 \mathrm{mg} / \mathrm{kg}$ diclofenac (day 3). (C) from the left to the right: Control and single dose $150 \mathrm{mg} / \mathrm{kg}$ diclofenac (day 1). Diclofenac induced a predominant sinusoidal expression of the CD68 antigen. We also investigated the morphology of sinusoidal endothelial cell (SEC) using the CD31 marker and found SECs to be intact (Images are not shown). Immunohistochemistry of the macrophage colony stimulating factor (mCSF) in livers of control and diclofenac treated mice. (D) from the left to the right: Control and single dose $30 \mathrm{mg} / \mathrm{kg}$ diclofenac (day 1). (E) from the left to the right: Control and repeated dose $30 \mathrm{mg} / \mathrm{kg}$ diclofenac (day 3). (F) from the left to the right: Control and repeated dose $30 \mathrm{mg} / \mathrm{kg}$ diclofenac (day 14). (G) from the left to the right: Control and repeated dose $150 \mathrm{mg} / \mathrm{kg}$ diclofenac (day 3). Magnifications 40x. 
repeated treatment.

Furthermore, significantly enriched ontology terms related to molecular and cellular functions were cellular movement, molecular transport, cell death, cellular assembly/organization after single treatment, whereas cellular movement, cell-to-cell signalling/interaction, antigen presentation, lipid metabolism and molecular transport were top functions after repeated treatment.

In the category physiological system, development and function significantly enriched terms were liver development and function, immune cell trafficking and tissue development with DEGs being related to hepatic system development and hematopoiesis as well as tissue morphology after single and repeated treatment. Finally, common ontology terms involved the hematological system development and function, inflammatory response and immune cell trafficking.

\section{Canonical pathway analysis}

Canonical pathway analysis was done with the molecular pathways tool available in the IPA library. After single treatment three metabolic pathways and seven signalling pathways were enriched and involved inositol phosphate, aminosugar, fructose and mannose metabolism. The signalling pathways were related to cellular immune responses, cytokine signalling, humoral immune responses, disease-specific pathway and the ingenuity toxicity list (Figure S3, Panel A). After repeated treatment the top 10 signalling pathways were concerned largely with apoptosis, cardiovascular signalling, cellular immune responses, cytokine signalling, disease-specific pathways, the ingenuity toxicity list, nuclear receptor signalling, and organismal growth development (Figure S3, Panel B).

Among the altered pathways, immune-related signalling was commonly affected and involved genes coding for Orm1, Orm2, Apcs, Serpina3, Stat3, and Lbp, along with Saa2 and Saa4. Additionally, interleukin signalling appeared in the canonical pathway analysis and involved genes coding for Stat3, Socs3, Il-33, Illrl and the chemokines $\mathrm{Cxcl3}$ and $\mathrm{Cxcl13}$.

\section{Regulatory gene networks}

Apart from the initial pathway analysis we searched for regulatory gene networks. This defined the growth hormone receptor $(G h r)$, leptin receptor (Lepr) and protein tyrosine phosphatase, non-receptor
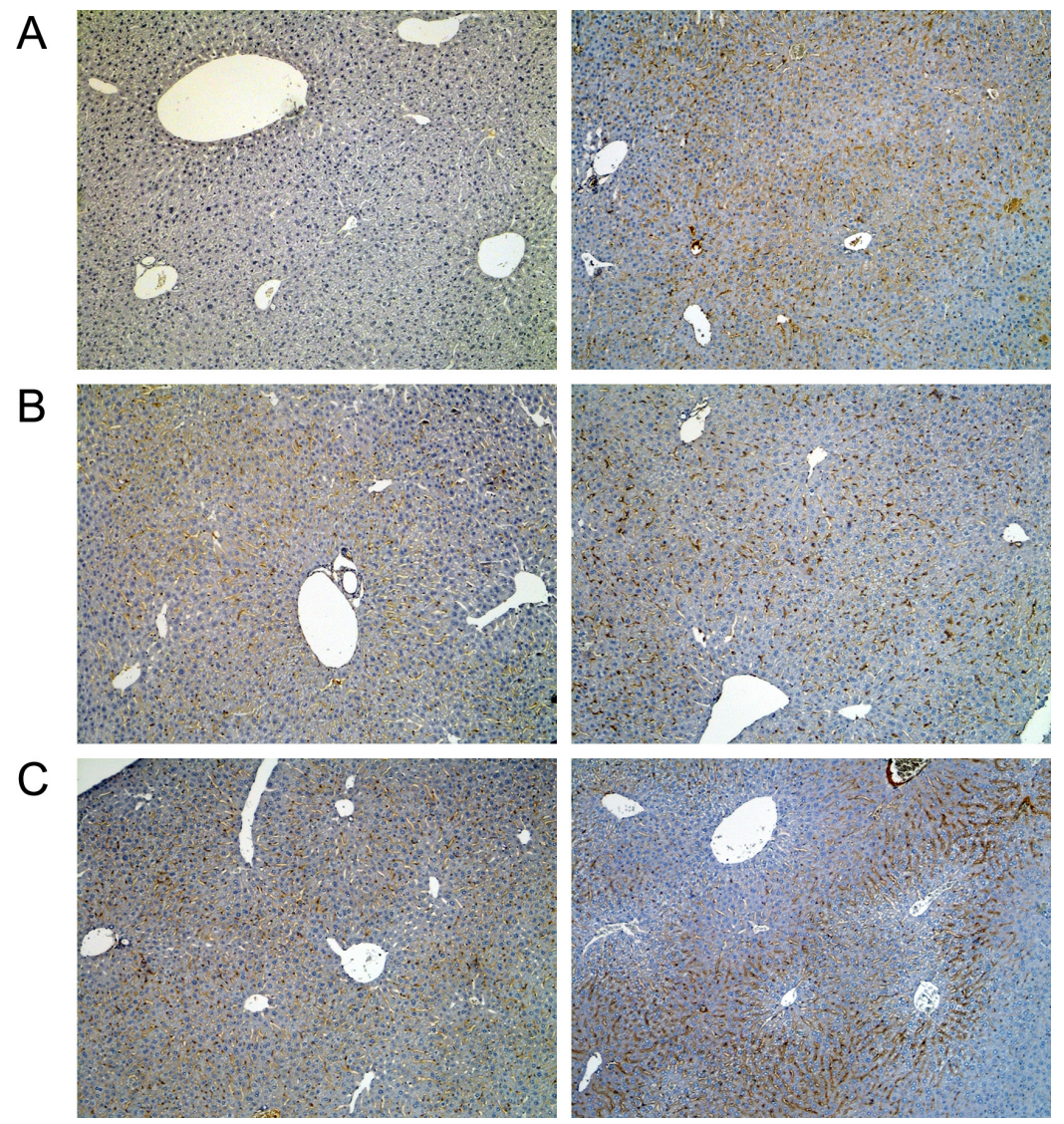

Figure 4: Immunohistochemistry of the lipopolysaccharide binding protein in livers of control and diclofenac treated mice. (A) from the left to the right: Control and single dose $30 \mathrm{mg} / \mathrm{kg}$ diclofenac (day 1). (B) from the left to the right: Control and repeated dose $30 \mathrm{mg} / \mathrm{kg}$ diclofenac (day 3). (C) from the left to the right: Control and single dose $150 \mathrm{mg} / \mathrm{kg}$ diclofenac (day 1). Magnifications 60x. 
type 2 (Ptpn2) as master regulators; their associated networks accounted for 140, 142 and 146 of significantly regulated DEGs or $>57 \%$ of total DEGs, respectively, after single treatment. Similarly, after repeated treatment $>50 \%$ of DEGs were connected in networks that consisted of the master regulators leptin receptor (Lepr), selectin (Sele) and suppressor of cytokine signalling 3 (Socs3). Moreover, common DEGs after single and repeated treatment for 3 days were grouped into networks with the leptin receptor, lipocaline 2 (Lcn2) and $N f k b$ as central acting molecules and accounted for $50 \%$ of significantly regulated DEGs. After 14 days of treatment the serum amyloid P-component (Apcs), CD44 antigen (Cd44) and cytotoxic $\mathrm{T}$ lymphocyte-associated protein 4 $(\mathrm{Ctla} 4)$ were defined as master regulators and involved $31 \%$ of DEGs in their associated networks. Note, the genes coding for the master regulators were likewise significantly regulated (see Table 3 ).

To search for cross-talk amongst individual regulatory gene networks an integrated network was constructed and $31 \%, 28 \%$ and $15 \%$ of DEGs were commonly regulated after single and repeated treatment, respectively (see Figures S4-S7). Intriguingly, the master regulatory molecules Lepr, Lcn2, Nfkbiz, Socs3, Apcs and Ctla4 were also significantly regulated in the fused network amongst all treatments.

\section{Validation studies by qRT-PCR, western blotting and immunohistochemistry}

Initially, a total of eight genes were selected with minor to moderate changes in gene expression to confirm their regulation by an independent method and except for Stat3, Fas and Ror-a there was agreement amongst both platforms in determining significant differences between control and diclofenac treated animals (Figure 11A). The regulation of genes coding for master regulators was also studied by qRT-PCR and the results are given in Figure 11B. Because of the variable responses amongst individual animals statistical significance could not be established even though some of the master regulators were $>10$-fold induced and the coded protein were significantly upregulated (see WB experiments below). Next regulation of
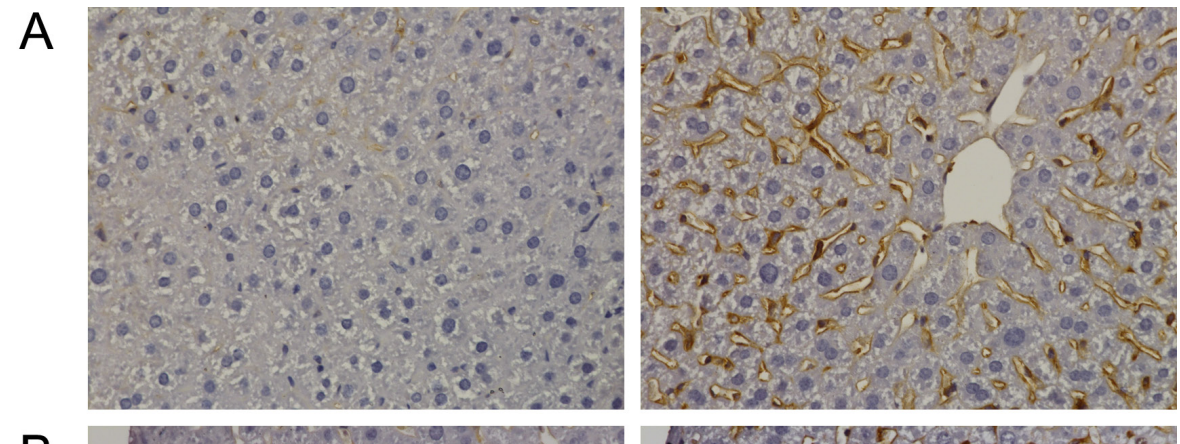

B
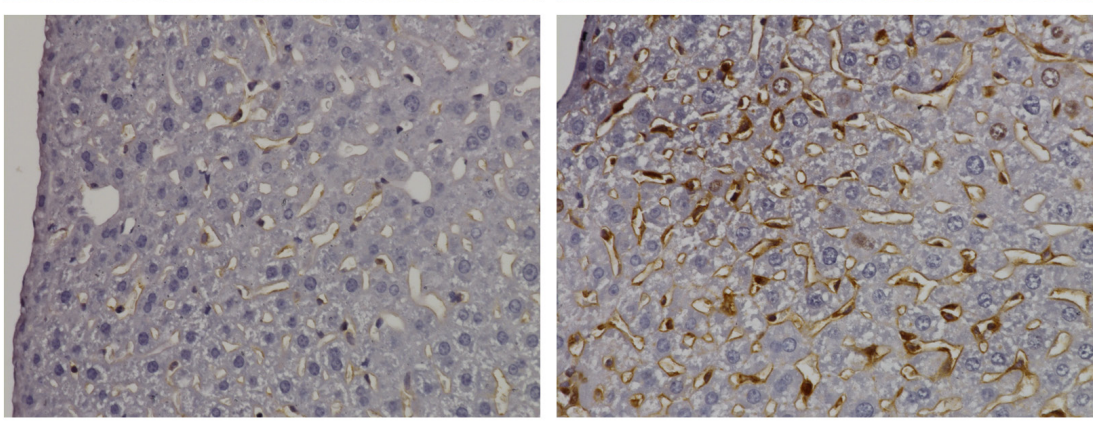

C
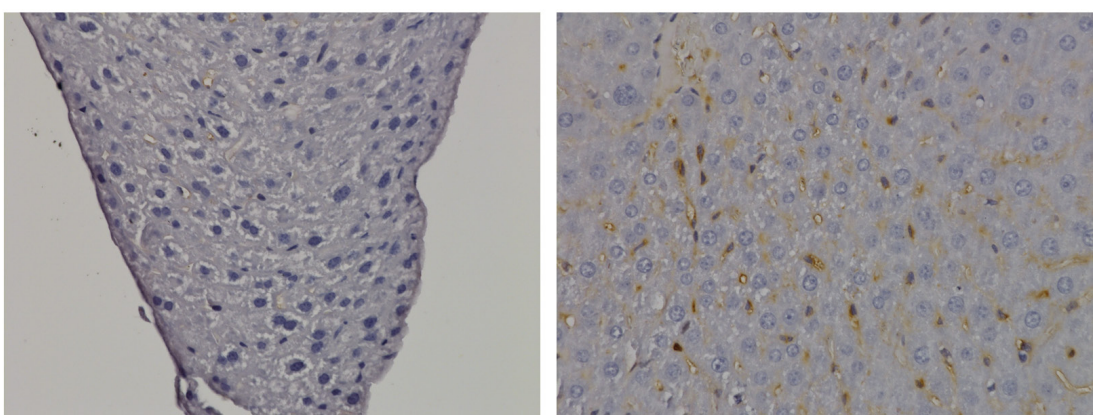

Figure 5: Immunohistochemistry of Ki67 in livers of control and diclofenac treated mice. (A) from the left to the right: Control and single dose $30 \mathrm{mg} / \mathrm{kg}$ diclofenac (day 1). (B) from the left to the right: Control and repeated dose $30 \mathrm{mg} / \mathrm{kg} \mathrm{diclofenac} \mathrm{(day} 3$ ). (C) from the left to the right: Control and single dose $150 \mathrm{mg} / \mathrm{kg}$ diclofenac (day 1). Magnifications 240x. 
cytokines was investigated by qRT-PCR (see Figure 11C and Table S9 for regulated cytokines and cluster of differentiation molecules found to be regulated by diclofenac) and trend wise the microarray and qRT-PCR data agreed; however, the data were more variable in qRT-PCR assays. Diclofenac treatment caused significant hepatic glycogen depletion (see hepatic PAS staining Figure $2 \mathrm{~B}$ and $2 \mathrm{C}$ ); we therefore studied regulation of genes involved in glycogenesis and carbohydrate metabolism. This revealed the genes hexokinase 1 (Hk1) and enolase 1 (Eno1) to be moderately but significantly regulated. Specifically, Hkl catalyses the production of glucose-6-phosphate, a rate limiting step in mitochondrial glycolysis as well as Eno1, which determines the conversion of 2-phosphoglycerate to phosphoenolpyruvate (see Figure S8).

Next Western immunoblotting studies were performed to reveal significant regulation of fibronectin, growth hormone receptor (oppositely on day 1 and 3) and M-CSF (Figure 12A and 12B) and although pSTAT3 expression was highly induced among individual animals it failed statistical significance testing. The extremely
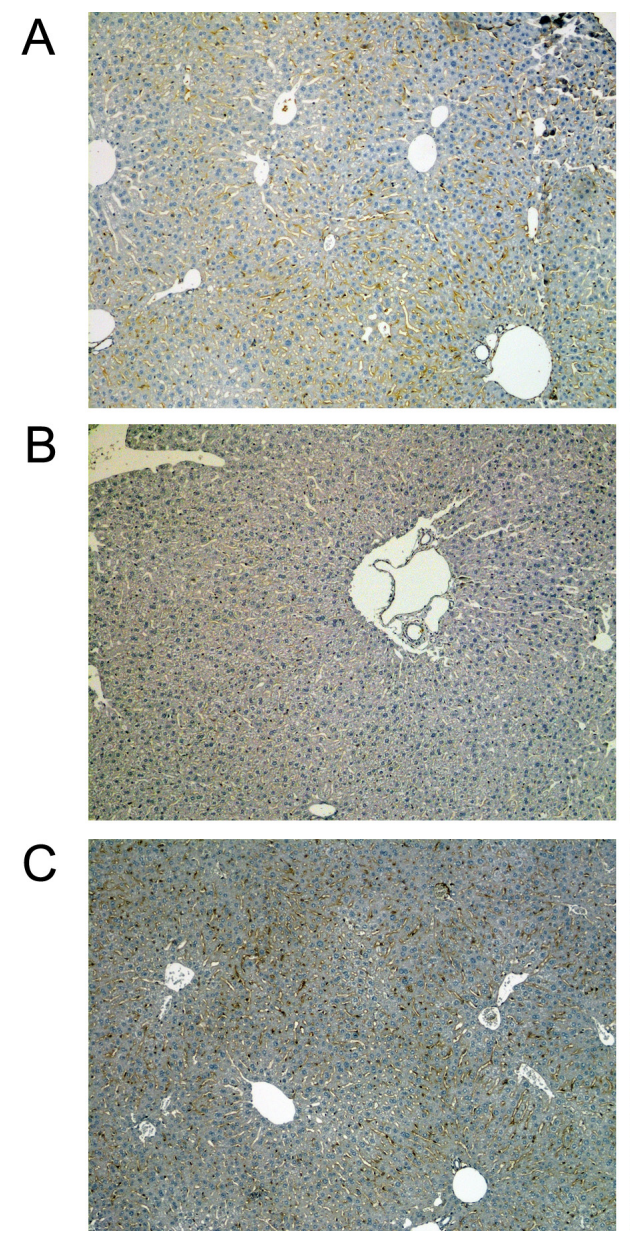

Figure 6: Immunohistochemistry of the T-cell protein tyrosine phosphatase in livers of control and diclofenac treated mice. (A) from the left to the right: Control and single dose $30 \mathrm{mg} / \mathrm{kg}$ diclofenac (day 1). (B) from the left to the right: Control and repeated dose $30 \mathrm{mg} / \mathrm{kg}$ diclofenac (day 3). (C) from the left to the right: Control and single dose $150 \mathrm{mg} / \mathrm{kg}$ diclofenac (day 1). Magnifications 60x.
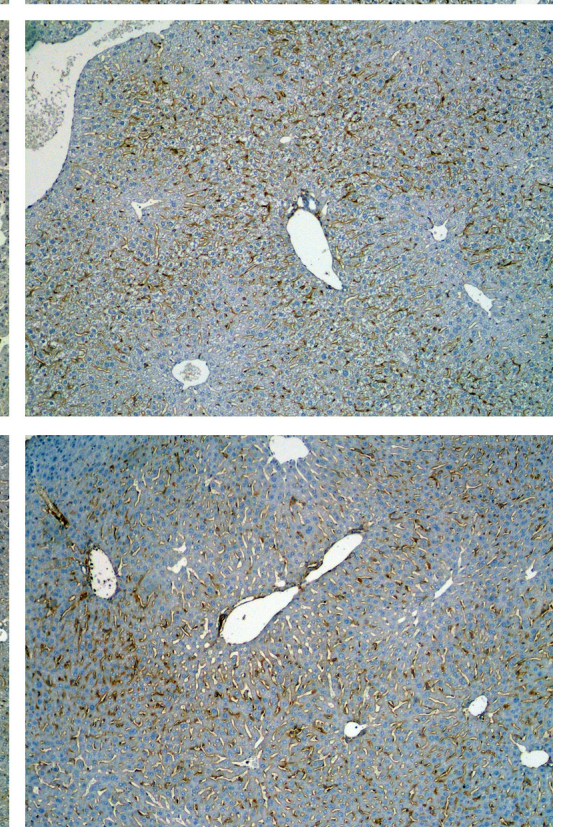

large scattering of phospho-Stat3 might be due to some oscillation in the phosphorylation of Stat 3 with animals not being synchronised in the circadian rhythm. After single diclofenac treatment, a small but statistically significant induction of TC-PTP was observed (see Figure $12 \mathrm{~A}$ and $12 \mathrm{~B}$ ) while Western blotting of master regulatory molecules after repeated diclofenac treatment for 14 days identified CD44, CTLA4 and APCS to be up-regulated; however only the latter two proteins reached statistical significance (Figure 12C).

The expression of master regulatory molecules was also studied by immunohistochemistry as detailed above.

\section{STRING PPI networks}

Protein-protein interactions (PPI) were determined with the String software version 9.1. Overall, 48\% of DEGs had proven PPIs after single and/or repeated treatment and therefore interact with each other. As diclofenac treatment influenced the expression of genes associated with inflammation, immune and stress response (see Table S2) individual PPI networks were constructed;

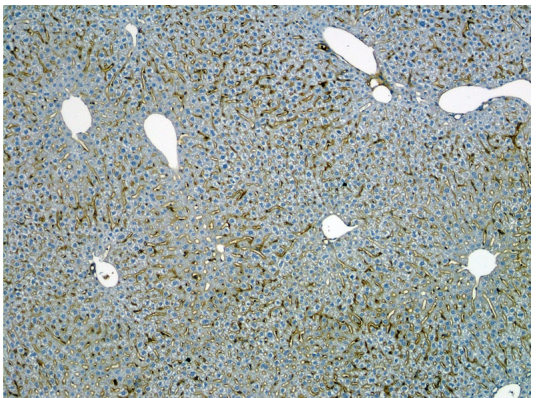


as shown in Figures $13 \mathrm{~A}-15 \mathrm{~A}$ the total numbers of PPIs were 749, 687, 1043 after single and repeated treatment for 3 and 14 days, respectively. Furthermore, the numbers of PPIs within the inflammation, immune and stress response networks were 75,107 and 282 after single (see Figure 13B-13D) and 89, 74, 256 after repeated treatment for 3 days (see Figure 14B-14D). Likewise, diclofenac treatment for 14 days was associated with 92, 96 and 413 PPIs, respectively (see Figure 15B-15D).

\section{Co-occupancy of transcription factor binding sites in promoters of regulated genes}

To define molecular circuits in inflammation the involvement of different transcription factor at gene specific promoters of inflammatory, immune and stress response genes was investigated and included computational analysis using position weight matrices available in the TRANSFAC database in addition to entrained genetic algorithms (see Table S10-S12). After single treatment and among 35 inflammatory responsive genes 28, 27, 34, 29, 23 and 17 were significantly enriched for Cebpd, Rbpjk, Gre, Gata, P300 and Pparg transcription factor binding sites, respectively (see Figure 13B) whereas at gene specific promoters of Orm2, Cxcl1, S100a8 and Hck, the entire composite module could be fitted. Similarly, after repeated diclofenac treatment for 3 days the composite module encompassed 37 inflammatory response genes with 25,14, 17, 8, 32 and 14 genes being significantly enriched for Ar, Nf1, Lxr, P53 and Cebpd transcription factor binding sites, respectively (Figure 14B). Next the composite module for common

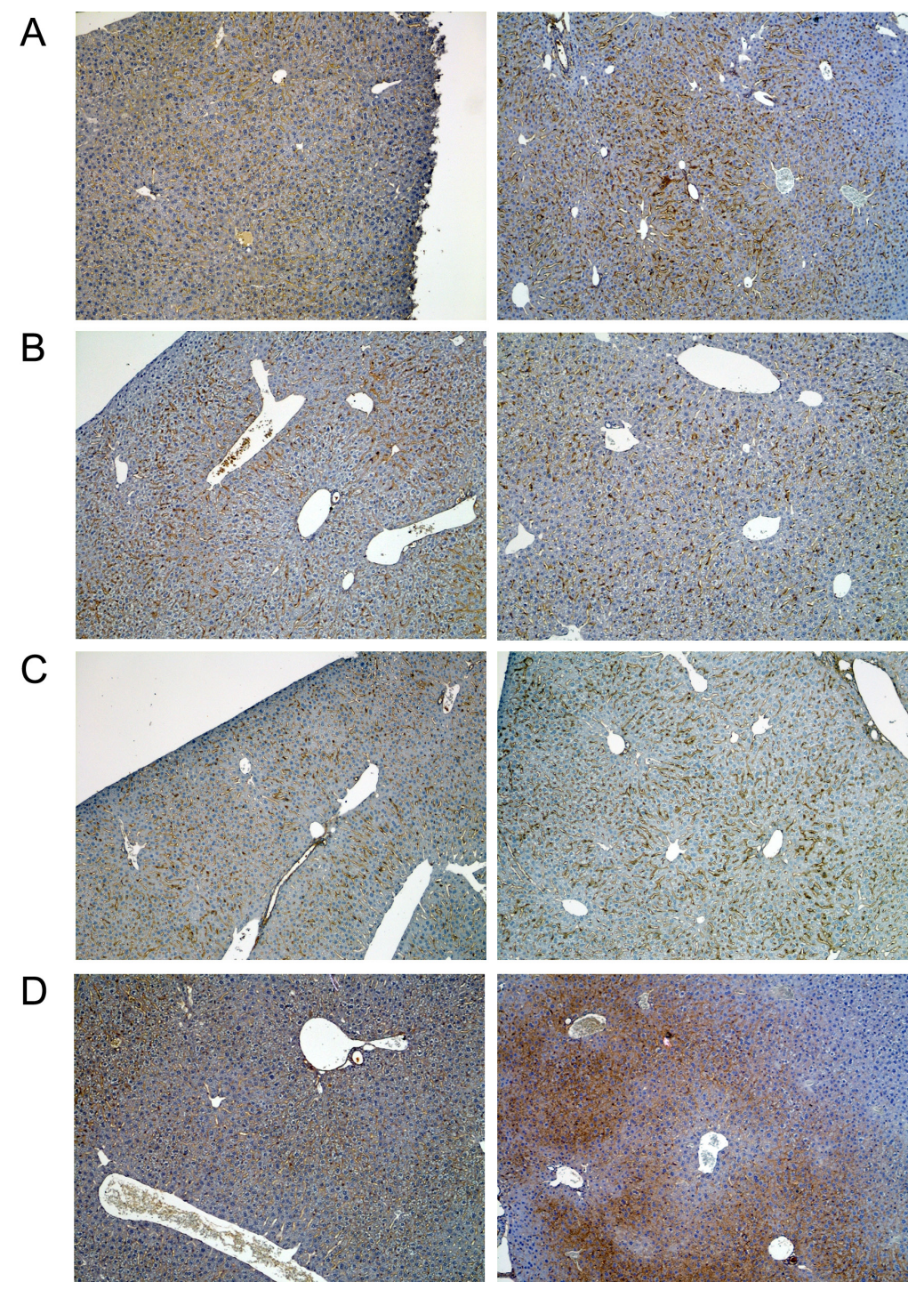

Figure 7: Immunohistochemistry of fibronectin in livers of control and diclofenac treated mice. (A) from the left to the right: Control and single dose $30 \mathrm{mg} / \mathrm{kg}$ diclofenac (day 1). (B) from the left to the right: Control and repeated dose $30 \mathrm{mg} / \mathrm{kg}$ diclofenac (day 3). (C) from the left to the right: Control and repeated dose $30 \mathrm{mg} / \mathrm{kg}$ diclofenac (day 14). (D) from the left to the right: Control and single dose $150 \mathrm{mg} / \mathrm{kg}$ diclofenac (day 1). Magnifications 50x. 
DEGs was computed and revealed significantly enriched Gata, Gfi1, Nf1, Cebpa and Drl transcription factor binding sites (Figure S9). Previous research already identified $\mathrm{C} / \mathrm{EBP}$ proteins to play a major role in the inflammatory response. After repeated treatment for 14 days inflammatory response genes involved the Coup1, Gatal, Vdr, Cdpcrl, Fxr and Ar transcription factors (Figure 15B). Conversely, promoters of the immune response genes were significantly enriched for Tcf11, Gre, Ppara, Gata4, Plzf and Ets TF binding sites after single (Figure 13C) and Ttf1, Gre, Pax8, Hnfalpha, Vdr and E12 after repeated treatment for 3 days (Figure 14C). Likewise, after 14 days of treatment the composite module consisted of the transcription factors Pebp2b (Cbfb), Tfe, Hnf4, Tcfl1 and $A r$ (Figure 15C).

When promoters of stress response regulated genes were interrogated the composite modules consisted of Cebpa, Gre, Wt1, Vdr and Cdpcrl after single (see Figure 13D) and Cebp, Dbp, Sp3, Gre, Ik and IpfI after repeated treatment for 3 days (Figure 14D). After 14 days of treatment a composite module was constructed and consisted of Blimp1, Pbx1, Aml1, Gata4 and Ipf1 transcription factors (Figure 15D). Note, the frequency of transcription factor binding sites in promoters of inflammatory, immune and stress response genes is given in Tables S13-S15.

\section{Studies with mouse hepatocyte cultures}

Whole genome gene expression profiling of diclofenac treated primary mouse hepatocytes cultures revealed 2663 (1371 up- and 1292 down-) DEGs with the fold change of $>2$ and $p$-value cut off of $<0.01$. Furthermore, the comparison of in vitro and in vivo data (day 1, 3 and 14) defined 20 genes to be regulated in common (see Figure S10), however Cxcl1, Dnajc12, Hp, Hsd3b5, Icam1, Il-33, Ly6e, Marco, Nfkbiz, Saa4, Serpina10, Steap4 and Tmem176a were oppositely regulated when compared to in vivo findings (Table S16).

\section{DISCUSSION}

Diclofenac is a commonly prescribed NSAID for the treatment of pain and inflammation; however, its use is associated with adverse drug reaction most notable increased risk for arterial thrombotic event that prompted

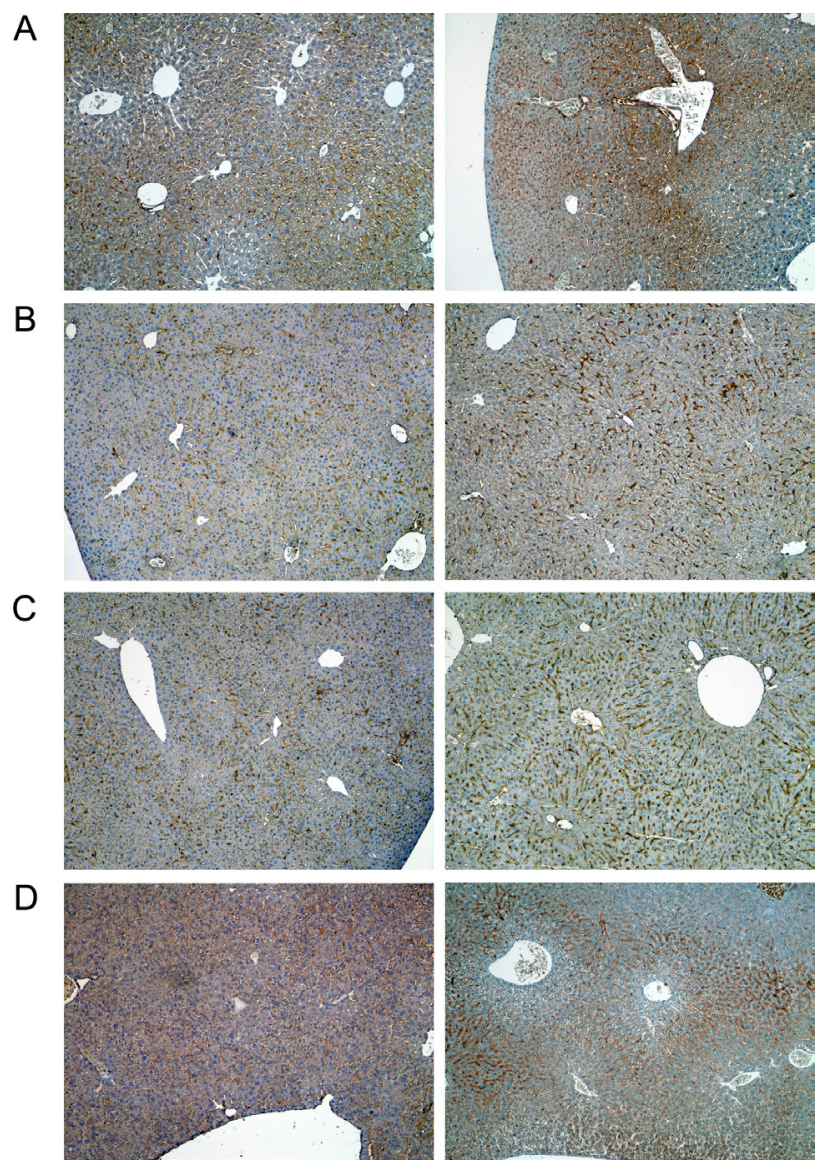

Figure 8: Immunohistochemistry of growth hormone receptor in livers of control and diclofenac treated mice. (A) from the left to the right: Control and single dose $30 \mathrm{mg} / \mathrm{kg}$ diclofenac (day 1). (B) from the left to the right: Control and repeated dose $30 \mathrm{mg} / \mathrm{kg}$ diclofenac (day 3). (C) from the left to the right: Control and repeated dose $30 \mathrm{mg} / \mathrm{kg}$ diclofenac (day 14). (D) from the left to the right: Control and single dose $150 \mathrm{mg} / \mathrm{kg}$ diclofenac (day 1). Magnifications 50x. 
new safety advice by the European Medicines Agency in 2013. Apart from cardiovascular complications its use is also associated with significant gastrointestinal toxicity and drug-induced liver injury (DILI) of different grades including rare but life-threatening acute liver failures that required liver transplantation as determined in a recently published retrospective study involving 52 centres across 7 European countries [14]. A newly published study on the incidence, presentation and outcome in patients of the general population of Iceland also revealed diclofenac to rank second amongst drugs causing DILI [15] while histopathology findings of clinical cases are suggestive for an immune allergic reaction type in diclofenac DILI cases.

In an effort to define immune-mediated mechanisms of hepatotoxicity we investigated genomic responses in livers of mice after single and repeated diclofenac treatment. This revealed key molecular processes whereby diclofenac elicits an inflammatory, acute phase and immune response. Our findings agree with the general notion on diclofenac hepatotoxicity whereby reactive metabolites and immune mediated mechanisms lead to liver injury [16].

Specifically, the potential to cause liver injury in mice was investigated at diclofenac doses of 50, 80 , and $120 \mathrm{mg} / \mathrm{kg}$ with serum transaminase activity being significantly increased at 80 and $120 \mathrm{mg} / \mathrm{kg}$ after 24 hours of treatment [10]. In this study diclofenacinduced liver injury was associated with regulation of $I l-1 \beta$ and in vivo blocking/neutralization of $I l-1 \beta$ activity with an inhibitory antibody ameliorated liver injury to suggest $I L-1 \beta$ to be involved in the pathogenesis of liver injury. In the present study and at the lower dose of $30 \mathrm{mg} / \mathrm{kg}$ body weight $I l-1 \beta$ was also significantly up-regulated (nearly 3-fold) after 14 days of treatment (see Table S9). At this dose significant changes in serum ALT, AST and ALP activities were observed, however $150 \mathrm{mg} / \mathrm{kg}$ induced mortality and acute liver failure. Therefore, our study evidences acute lethality at significantly lower doses to the previously reported LD50 of $345 \mathrm{mg} / \mathrm{kg}$ [TOXNET Database: http://chem.sis. nlm.nih.gov/chemidplus/rn/15307-86-5].

Owing to its extensive metabolism we initially assessed regulation of genes coding for drug metabolism and transport, however observed only minor, yet statistically significant changes after diclofenac treatment (see Table S3). Furthermore, the expression of Sod2 was decreased in diclofenac-treated livers and this enzyme transforms toxic superoxide into hydrogen peroxide and oxygen in mitochondria. Decreased expression levels of Sod2 are associated with oxidative stress as was shown in a previous performed hepatocyte cell culture study where production of reactive oxygen species (ROS) increased upon diclofenac treatment [5].

Diclofenac treatment induced innate and adaptive immune responses [10,17-19] as demonstrated in the present study by the regulation of various chemokines Cxcl1, Cxcl2, Cxcl13, Xcl1, Ccl6, Tnfaip8l2, Tnfsf12/13, Il-7, Il-15 and cytokine receptors Illr1, Il4ra, Fas
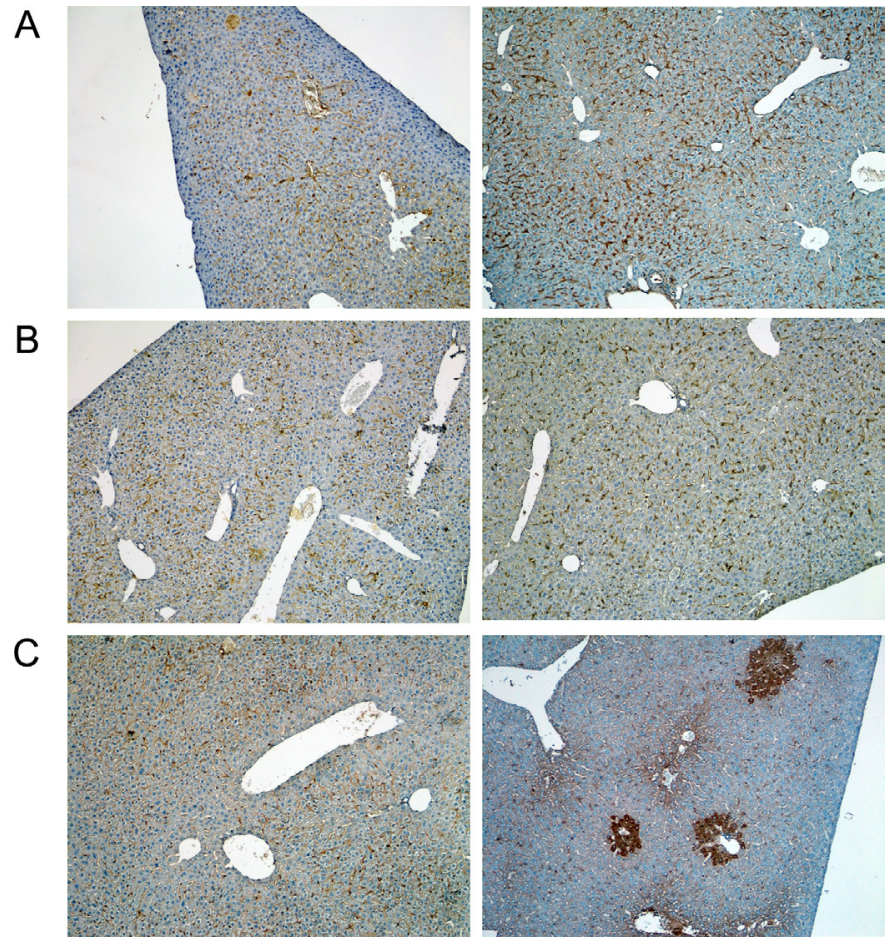

Figure 9: Immunohistochemistry of the leptin receptor in livers of control and diclofenac treated mice. (A) from the left to the right: Control and single dose $30 \mathrm{mg} / \mathrm{kg}$ diclofenac (day 1). (B) from the left to the right: Control and repeated dose $30 \mathrm{mg} / \mathrm{kg}$ diclofenac (day 3). (C) from the left to the right: Control and repeated dose $150 \mathrm{mg} / \mathrm{kg}$ diclofenac (day 2). Magnifications $50 x$. 
Table 2A: Commonly regulated immune, inflammatory and stress response genes after single and repeated diclofenac treatment for 3 days

\begin{tabular}{|c|c|c|c|}
\hline \multirow{2}{*}{ ID } & \multirow{2}{*}{ Gene description } & \multicolumn{2}{|c|}{ Fold Change } \\
\hline & & Day 1 & Day 3 \\
\hline \multicolumn{4}{|c|}{ Inflammatory and immune response } \\
\hline Apcs* & Serum amyloid p-component & 4.28 & 3.92 \\
\hline Ccl6 & Chemokine (c-c motif) ligand 6 & 2.99 & 1.68 \\
\hline Chi313* & Chitinase 3-like 3 & 3.9 & 3.89 \\
\hline Ctsc & Cathepsin c & 1.95 & 2.40 \\
\hline $\mathrm{Cxcl}{ }^{*}$ & Chemokine (c-X-c motif) ligand 1 & 17.36 & 19.10 \\
\hline Cxcl13* & Chemokine (c-X-c motif) ligand 13 & 1.98 & 2.02 \\
\hline $\mathrm{Hp}^{*}$ & Haptoglobin & 1.43 & 1.57 \\
\hline Ifitm2 & Interferon induced transmembrane protein 2 & 1.67 & 1.51 \\
\hline Il33 & Interleukin 33 & 1.74 & 1.54 \\
\hline Itih4* & Inter alpha-trypsin inhibitor, heavy chain 4 & 1.51 & 1.55 \\
\hline $\mathrm{Lbp}^{*}$ & Lipopolysaccharide binding protein & 1.88 & 1.67 \\
\hline $\operatorname{Lcn} 2$ & Lipocalin 2 & 22.49 & 18.37 \\
\hline Marco & Macrophage receptor with collagenous structure & 4.00 & 1.98 \\
\hline Nfkbiz* & $\begin{array}{l}\text { Nuclear factor of kappa light polypeptide gene enhancer in b-cells inhibitor, } \\
\text { zeta }\end{array}$ & 2.90 & 1.69 \\
\hline Orm $1 *$ & Orosomucoid 1 & 1.72 & 1.52 \\
\hline Orm2* & Orosomucoid 2 & 8.46 & 10.83 \\
\hline Orm3 & Orosomucoid 3 & 9.01 & 3.48 \\
\hline $\operatorname{Prg} 4$ & $\begin{array}{l}\text { Proteoglycan } 4 \text { (megakaryocyte stimulating factor, articular superficial zone } \\
\text { protein) }\end{array}$ & 4.18 & 2.74 \\
\hline S100a8* & S100 calcium binding protein a8 (calgranulin a) & 14.02 & 7.46 \\
\hline S100a9* & S100 calcium binding protein a9 (calgranulin b) & 8.54 & 4.13 \\
\hline Saa $1 *$ & Serum amyloid a 1 & 4.58 & 9.97 \\
\hline Saa2* & Serum amyloid a 2 & 9.83 & 35.20 \\
\hline Saa3* & Serum amyloid a 3 & 6.89 & 4.39 \\
\hline Saa4* & Serum amyloid a 4 & 1.78 & 2.18 \\
\hline Serpina3n* & Serine (or cysteine) peptidase inhibitor, clade a, member $3 n$ & 4.60 & 3.24 \\
\hline Stat3* & Signal transducer and activator of transcription 3 & 1.93 & 2.08 \\
\hline Tfre* & Transferrin receptor & 1.77 & 1.85 \\
\hline $\mathrm{Ubc}^{*}$ & Ubiquitin c & 1.74 & -1.47 \\
\hline Vcam1 & Vascular cell adhesion molecule 1 & 1.46 & 1.84 \\
\hline \multicolumn{4}{|c|}{ Stress response } \\
\hline Clec2h & C-type lectin domain family 2 , member $\mathrm{h}$ & -2.60 & -2.47 \\
\hline Fabp5 & Fatty acid binding protein 5 , epidermal & 3.08 & 1.68 \\
\hline Hspala & Heat shock protein $1 \mathrm{a}$ & 1.71 & -1.45 \\
\hline Icam1 & Intercellular adhesion molecule 1 & 1.75 & 1.85 \\
\hline Lepr & Leptin receptor & 2.00 & -1.66 \\
\hline
\end{tabular}




\begin{tabular}{|c|c|c|c|}
\hline Plac8 & Placenta-specific 8 & 2.00 & 1.68 \\
\hline Ptpn1 & Protein tyrosine phosphatase, non-receptor type 1 & 1.59 & 1.62 \\
\hline Scara5 & Scavenger receptor class a, member 5 (putative) & 4.11 & 2.54 \\
\hline Socs3 & Suppressor of cytokine signaling 3 & 3.05 & 3.43 \\
\hline \multicolumn{4}{|c|}{ Regulation of Cell death } \\
\hline Gas1 & Growth arrest specific 1 & -1.58 & -1.81 \\
\hline Litaf & Lps-induced tn factor & 1.87 & 2.06 \\
\hline Phlda1 & Pleckstrin homology-like domain, family a, member 1 & -1.72 & -1.57 \\
\hline Tsc22d1 & Tsc22 domain family, member 1 & -1.67 & -1.55 \\
\hline \multicolumn{4}{|c|}{ Drug metabolism and detoxification pathways } \\
\hline Aldh18a1 & Aldehyde dehydrogenase 18 family, member a1 & 2.37 & 1.64 \\
\hline Ces1d & Carboxylesterase $1 \mathrm{~d}$ & -1.87 & -2.88 \\
\hline Ces1e & Carboxylesterase $1 \mathrm{e}$ & -1.76 & -1.55 \\
\hline Cyp26a1 & Cytochrome p450, family 26 , subfamily a, polypeptide 1 & -2.23 & -2.71 \\
\hline Cyp3a13 & Cytochrome p450, family 3 , subfamily a, polypeptide 13 & 1.75 & 1.57 \\
\hline Cyb561 & Cytochrome b-561 & 4.26 & 2.79 \\
\hline Gstt3 & Glutathione s-transferase, theta 3 & -1.78 & 1.49 \\
\hline Hsd3b5 & $\begin{array}{l}\text { Hydroxy-delta-5-steroid dehydrogenase, } 3 \text { beta- and steroid delta-isomerase } \\
5\end{array}$ & -2.42 & -1.63 \\
\hline Qsox1 & Quiescin q6 sulfhydryl oxidase 1 & 1.88 & 1.58 \\
\hline Sqle & Squalene epoxidase & 1.90 & 2.42 \\
\hline Steap4 & Steap family member 4 & 3.02 & 4.81 \\
\hline Ugt2b38 & UDP glucuronosyltransferase 2 family, polypeptide B38 & -1.53 & -2.85 \\
\hline Upp2 & Uridine phosphorylase 2 & -1.61 & -1.95 \\
\hline \multicolumn{4}{|c|}{ Cellular homeostasis } \\
\hline Ibtk & Inhibitor of bruton agammaglobulinemia tyrosine kinase & 1.82 & 1.61 \\
\hline Mt1 & Metallothionein 1 & 2.45 & 2.06 \\
\hline Mt2 & Metallothionein 2 & 2.61 & 2.19 \\
\hline Pdilt & Protein disulfide isomerase-like, testis expressed & -1.71 & -1.59 \\
\hline \multicolumn{4}{|c|}{ GPCR protein signaling pathway } \\
\hline Gnat1 & Guanine nucleotide binding protein, alpha transducing 1 & 2.90 & 3.20 \\
\hline Lpar4 & Lysophosphatidic acid receptor 4 & -1.53 & 1.44 \\
\hline Ptgfr & Prostaglandin f receptor & -1.53 & 1.63 \\
\hline Sucnr1 & Succinate receptor 1 & -2.24 & -1.67 \\
\hline \multicolumn{4}{|c|}{\begin{tabular}{|l|} 
Jak-Stat signalling pathway \\
\end{tabular}} \\
\hline Csf2rb & \begin{tabular}{|l} 
Colony stimulating factor 2 receptor, beta, low-affinity (granulocyte- \\
macrophage)
\end{tabular} & 2.71 & 1.59 \\
\hline Csf2rb2 & $\begin{array}{l}\text { Colony stimulating factor } 2 \text { receptor, beta } 2 \text {, low-affinity (granulocyte- } \\
\text { macrophage) }\end{array}$ & 2.44 & 1.52 \\
\hline Il13ra1 & Interleukin 13 receptor, alpha 1 & 2.30 & 1.88 \\
\hline Lifr & Leukemia inhibitory factor receptor & -1.60 & -1.76 \\
\hline Spry4 & Sprouty homolog 4 (drosophila) & -1.55 & -2.74 \\
\hline
\end{tabular}




\begin{tabular}{|c|c|c|c|}
\hline \multicolumn{4}{|c|}{ Transporter activity } \\
\hline Atp11a & Atpase, class vi, type 11a & 2.83 & 1.82 \\
\hline Fabp2 & Fatty acid binding protein 2 , intestinal & -1.77 & -1.81 \\
\hline Mup4 & Major urinary protein 4 & -1.60 & -1.53 \\
\hline Nipal1 & Nipa-like domain containing 1 & 4.26 & 2.05 \\
\hline Slc16a5 & Solute carrier family 16 (monocarboxylic acid transporters), member 5 & 1.56 & 1.53 \\
\hline Slc25a30 & Solute carrier family 25 , member 30 & -1.75 & -2.10 \\
\hline Slc3a1 & Solute carrier family 3 , member 1 & 2.60 & 2.24 \\
\hline Slc41a2 & Solute carrier family 41, member 2 & 3.58 & 2.74 \\
\hline Slcola1 & Solute carrier organic anion transporter family, member 1a1 & -1.77 & -1.76 \\
\hline Slcola4 & Solute carrier organic anion transporter family, member 1a4 & -1.50 & -1.43 \\
\hline Timm8a2 & Translocase of inner mitochondrial membrane 8 homolog a2 (yeast) & 1.54 & -1.43 \\
\hline \multicolumn{4}{|c|}{ Metabolic processes } \\
\hline 4930444A02Rik & Riken cdna 4930444a02 gene & 1.59 & 1.43 \\
\hline Acpp & Acid phosphatase, prostate & 2.45 & 1.77 \\
\hline Adck3 & Aarf domain containing kinase 3 & -1.92 & -1.53 \\
\hline Agxt211 & Alanine-glyoxylate aminotransferase 2-like 1 & -1.79 & -2.18 \\
\hline Arid5b & At rich interactive domain $5 \mathrm{~b}$ (mrfl-like) & -2.04 & -1.63 \\
\hline B3galt1 & Udp-gal:betaglcnac beta 1,3-galactosyltransferase, polypeptide 1 & 3.53 & 7.23 \\
\hline $\mathrm{BC} 048546$ & Cdna sequence bc 048546 & 2.42 & 1.67 \\
\hline Car1 & Carbonic anhydrase 1 & -1.80 & -1.46 \\
\hline Car13 & Carbonic anhydrase 13 & -1.67 & 1.49 \\
\hline Ctsj & Cathepsin $\mathrm{j}$ & 3.68 & 1.50 \\
\hline Eifla & Eukaryotic translation initiation factor $1 \mathrm{a}$ & 1.97 & 1.69 \\
\hline Fgl1 & Fibrinogen-like protein 1 & 2.17 & 1.96 \\
\hline Hes6 & Hairy and enhancer of split 6 (drosophila) & -1.61 & -1.61 \\
\hline Hs6st2 & Heparan sulfate 6-o-sulfotransferase 2 & 1.42 & 1.47 \\
\hline Inmt & Indolethylamine n-methyltransferase & -1.79 & -1.52 \\
\hline Isyna1 & Myo-inositol 1-phosphate synthase a1 & 5.21 & 1.86 \\
\hline Itih3 & Inter-alpha trypsin inhibitor, heavy chain 3 & 1.81 & 1.64 \\
\hline Lass6 & Lag1 homolog, ceramide synthase 6 & 2.24 & 2.68 \\
\hline Ly6e & Lymphocyte antigen 6 complex, locus e & 1.58 & 1.69 \\
\hline Mme & Membrane metallo endopeptidase & -2.14 & -1.54 \\
\hline Mmp16 & Matrix metallopeptidase 16 & 1.58 & 1.84 \\
\hline Nnmt & Nicotinamide n-methyltransferase & 2.47 & 1.81 \\
\hline Nova1 & Neuro-oncological ventral antigen 1 & -1.55 & 1.42 \\
\hline Prtn3 & Proteinase 3 & 8.84 & 3.72 \\
\hline Rp1391 & Ribosomal protein 139-like & 1.69 & 1.45 \\
\hline Stk31 & Serine threonine kinase 31 & -1.47 & 1.51 \\
\hline Tgm1 & Transglutaminase 1 , k polypeptide & 1.63 & 1.93 \\
\hline Tspan8 & Tetraspanin 8 & 1.75 & 1.63 \\
\hline
\end{tabular}




\begin{tabular}{|c|c|c|c|}
\hline \multicolumn{4}{|c|}{ Regulation of signalling } \\
\hline D0H4S114 & Dna segment, human $\mathrm{d} 4 \mathrm{~s} 114$ & -2.30 & -1.96 \\
\hline $\operatorname{Lrg} 1$ & Leucine-rich alpha-2-glycoprotein 1 & 2.30 & 2.26 \\
\hline Tcl1b3 & T-cell leukemia/lymphoma $1 \mathrm{~b}, 3$ & 2.61 & 1.80 \\
\hline Tifa & Traf-interacting protein with forkhead-associated domain & 1.86 & 3.52 \\
\hline Tspan4 & Tetraspanin 4 & 1.68 & 1.92 \\
\hline Vwce & Von Willebrand factor C and EGF domains & -2.01 & -1.72 \\
\hline \multicolumn{4}{|c|}{ Binding activity } \\
\hline Cpne8 & Copine viii & 3.44 & 2.48 \\
\hline Dnajc12 & Dnaj (hsp40) homolog, subfamily c, member 12 & 3.29 & 2.70 \\
\hline Edil3 & Egf-like repeats and discoidin i-like domains 3 & -1.56 & -1.46 \\
\hline Ifitm6 & Interferon induced transmembrane protein 6 & 3.36 & 1.69 \\
\hline Klrb1b & Killer cell lectin-like receptor subfamily b member $1 \mathrm{~b}$ & 1.72 & 1.43 \\
\hline Mpeg1 & Macrophage expressed gene 1 & 2.37 & 1.56 \\
\hline Opcml & Opioid binding protein/cell adhesion molecule-like & 1.45 & 1.47 \\
\hline Rab11fip3 & Rab11 family interacting protein 3 (class ii) & 1.52 & 1.42 \\
\hline Rpap3 & Rna polymerase ii associated protein 3 & 2.59 & 1.69 \\
\hline Serpina10 & $\begin{array}{l}\text { Serine (or cysteine) peptidase inhibitor, clade a (alpha-1 antiproteinase, } \\
\text { antitrypsin), member } 10\end{array}$ & 1.95 & 1.91 \\
\hline Snx 10 & Sorting nexin 10 & 1.78 & 1.95 \\
\hline Tmem176a & Transmembrane protein $176 \mathrm{a}$ & 1.79 & 1.52 \\
\hline \multicolumn{4}{|c|}{ Cellular development and differentiation } \\
\hline Fam55d & Family with sequence similarity 55, member $\mathrm{d}$ & 1.56 & 1.51 \\
\hline Fndc3b & Fibronectin type iii domain containing $3 \mathrm{~b}$ & 2.99 & 2.04 \\
\hline Lceld & Late cornified envelope $1 \mathrm{~d}$ & -1.84 & 1.68 \\
\hline Mtap7d1 & Microtubule-associated protein 7 domain containing 1 & 1.61 & 1.77 \\
\hline Phyhipl & Phytanoyl-coa hydroxylase interacting protein-like & -1.49 & 1.92 \\
\hline Sema4b & $\begin{array}{l}\text { Sema domain, immunoglobulin domain (ig), transmembrane domain (tm) } \\
\text { and short cytoplasmic domain, (semaphorin) } 4 \mathrm{~b}\end{array}$ & 1.44 & 1.67 \\
\hline Shisa6 & Shisa homolog 6 (xenopus laevis) & -1.45 & -1.62 \\
\hline
\end{tabular}

Mice were treated with $30 \mathrm{mg} / \mathrm{kg}$ diclofenac once daily for up to 3 days. Whole genome microarray studies were performed and analyzed as detailed in the Material and Method section. 132 statistically significantly regulated genes $(p<0.01)$ were in common when single and repeated treatment groups were compared.

*The marked genes are also involved in stress response.

Table 2B: Commonly regulated immune, inflammatory and stress response genes after single and repeated diclofenac treatment for 14 days

\begin{tabular}{|c|c|c|c|c|}
\hline \multirow{2}{*}{ ID } & \multirow{2}{*}{ Gene description } & \multicolumn{3}{|c|}{ Fold Change } \\
\hline & & Day 1 & Day 3 & Day 14 \\
\hline \multicolumn{5}{|c|}{ Inflammation and immune response } \\
\hline Apcs* & Serum amyloid p-component & 4.28 & 3.92 & 6.77 \\
\hline Ccl6 & Chemokine (C-C motif) ligand 6 & 2.99 & 1.68 & 3.66 \\
\hline Cxcl1* & Chemokine (C-X-C motif) ligand 1 & 17.36 & 19.10 & 25.73 \\
\hline Cxcl13* & Chemokine (C-X-C motif) ligand 13 & 1.98 & 2.02 & 14.62 \\
\hline
\end{tabular}




\begin{tabular}{|c|c|c|c|c|}
\hline $\mathrm{Hp} *$ & Haptoglobin & 1.43 & 1.57 & 1.44 \\
\hline Il33 & Interleukin 33 & 1.74 & 1.54 & 4.41 \\
\hline Itih4* & Inter alpha-trypsin inhibitor, heavy chain 4 & 1.51 & 1.55 & 2.18 \\
\hline Lcn2* & Lipocalin 2 & 22.49 & 18.37 & 12.11 \\
\hline Lbp* & Lipopolysaccharide binding protein & 1.88 & 1.67 & -1.69 \\
\hline Marco* & Macrophage receptor with collagenous structure & 4.00 & 1.98 & 7.20 \\
\hline Nfkbiz* & $\begin{array}{l}\text { Nuclear factor of kappa light polypeptide gene enhancer in B-cells } \\
\text { inhibitor, zeta }\end{array}$ & 2.90 & 1.69 & 3.33 \\
\hline Orm1* & Orosomucoid 1 & 1.72 & 1.52 & 2.28 \\
\hline Orm2* & Orosomucoid 2 & 8.46 & 10.83 & 8.19 \\
\hline $\operatorname{Prg} 4$ & $\begin{array}{l}\text { Proteoglycan } 4 \text { (megakaryocyte stimulating factor, articular superficial } \\
\text { zone protein) }\end{array}$ & 4.18 & 2.74 & 4.91 \\
\hline S100a9* & S100 calcium binding protein A9 (calgranulin B) & 8.54 & 4.13 & 10.66 \\
\hline Saa3* & Serum amyloid A 3 & 6.89 & 4.39 & 14.33 \\
\hline Saa4* & Serum amyloid A 4 & 1.78 & 2.18 & 2.30 \\
\hline Serpina3n* & Serine (or cysteine) peptidase inhibitor, clade A, member $3 \mathrm{~N}$ & 4.60 & 3.24 & 4.65 \\
\hline Stat3* & Signal transducer and activator of transcription 3 & 1.93 & 2.08 & 1.99 \\
\hline Tfre* & Transferrin receptor & 1.77 & 1.85 & 2.72 \\
\hline \multicolumn{5}{|c|}{ Stress response } \\
\hline Hspa1a & Heat shock protein $1 \mathrm{~A}$ & 1.71 & -1.45 & 1.68 \\
\hline Icam1 & Intercellular adhesion molecule 1 & 1.75 & 1.85 & 2.01 \\
\hline Plac8 & Placenta-specific 8 & 2.00 & 1.68 & 2.29 \\
\hline Ptpn1 & Protein tyrosine phosphatase, non-receptor type 1 & 1.59 & 1.62 & 1.65 \\
\hline Socs3 & Suppressor of cytokine signaling 3 & 3.05 & 3.43 & 7.78 \\
\hline \multicolumn{5}{|c|}{ Drug metabolism and detoxification pathways } \\
\hline Ces1d & Carboxylesterase 1D & -1.87 & -2.88 & -1.97 \\
\hline Ces1e & Carboxylesterase 1E & -1.76 & -1.55 & -1.87 \\
\hline Cyb561 & Cytochrome b-561 & 4.26 & 2.79 & 4.42 \\
\hline Hsd3b5 & $\begin{array}{l}\text { Hydroxy-delta-5-steroid dehydrogenase, } 3 \text { beta- and steroid delta- } \\
\text { isomerase } 5\end{array}$ & -2.42 & -1.63 & -1.43 \\
\hline Mt1 & Metallothionein 1 & 2.45 & 2.06 & 1.83 \\
\hline Mt2 & Metallothionein 2 & 2.61 & 2.19 & 2.21 \\
\hline Qsox1 & Quiescin Q6 sulfhydryl oxidase 1 & 1.88 & 1.58 & 2.15 \\
\hline Sqle & Squalene epoxidase & 1.90 & 2.42 & 6.79 \\
\hline Steap4 & STEAP family member 4 & 3.02 & 4.81 & 14.58 \\
\hline Upp2 & Uridine phosphorylase 2 & -1.61 & -1.95 & -1.56 \\
\hline \multicolumn{5}{|c|}{ Transporter activity } \\
\hline Atp11a & ATPase, class VI, type 11A & 2.83 & 1.82 & 5.46 \\
\hline Fabp2 & Fatty acid binding protein 2 , intestinal & -1.77 & -1.81 & -1.66 \\
\hline Slc3a1 & Solute carrier family 3, member 1 & 2.60 & 2.24 & 3.76 \\
\hline Slc41a2 & Solute carrier family 41, member 2 & 3.58 & 2.74 & 7.28 \\
\hline Slcola1 & Solute carrier organic anion transporter family, member 1a1 & -1.77 & -1.76 & -1.70 \\
\hline Slco1a4 & Solute carrier organic anion transporter family, member 1a4 & -1.50 & -1.43 & -1.54 \\
\hline
\end{tabular}




\begin{tabular}{|c|c|c|c|c|}
\hline Slc25a30 & Solute carrier family 25, member 30 & -1.75 & -2.10 & -1.64 \\
\hline \multicolumn{5}{|c|}{ Regulation of Cell death } \\
\hline Gas1 & Growth arrest specific 1 & -1.58 & -1.81 & -1.51 \\
\hline Tsc22d1 & TSC22 domain family, member 1 & -1.67 & -1.55 & -1.43 \\
\hline \multicolumn{5}{|c|}{ Response to cytokine stimulus } \\
\hline Il13ra1 & Interleukin 13 receptor, alpha 1 & 2.30 & 1.88 & 2.56 \\
\hline Mme & Membrane metallo endopeptidase & -2.14 & -1.54 & -1.81 \\
\hline \multicolumn{5}{|c|}{ Metabolic processes } \\
\hline Acpp & Acid phosphatase, prostate & 2.45 & 1.77 & 3.03 \\
\hline Agxt211 & Alanine-glyoxylate aminotransferase 2-like 1 & -1.79 & -2.18 & -3.16 \\
\hline B3galt1 & UDP-Gal:betaGlcNAc beta 1,3-galactosyltransferase, polypeptide 1 & 3.53 & 7.23 & 8.21 \\
\hline Car1 & Carbonic anhydrase 1 & -1.80 & -1.46 & -1.53 \\
\hline Ctsj & Cathepsin J & 3.68 & 1.50 & 1.89 \\
\hline Eif1a & Eukaryotic translation initiation factor $1 \mathrm{~A}$ & 1.97 & 1.69 & 1.55 \\
\hline Fgl1 & Fibrinogen-like protein 1 & 2.17 & 1.96 & 2.89 \\
\hline Inmt & Indolethylamine N-methyltransferase & -1.79 & -1.52 & -2.38 \\
\hline Isyna1 & Myo-inositol 1-phosphate synthase A1 & 5.21 & 1.86 & 2.76 \\
\hline Itih3 & Inter-alpha trypsin inhibitor, heavy chain 3 & 1.81 & 1.64 & 1.87 \\
\hline Ly6e & Lymphocyte antigen 6 complex, locus E & 1.58 & 1.69 & 2.40 \\
\hline Prtn3 & Proteinase 3 & 8.84 & 3.72 & 2.67 \\
\hline Stk31 & Serine threonine kinase 31 & -1.47 & 1.51 & 1.57 \\
\hline Sucnr1 & Succinate receptor 1 & -2.24 & -1.67 & -1.58 \\
\hline Tgm1 & Transglutaminase 1 , K polypeptide & 1.63 & 1.93 & 2.21 \\
\hline \multicolumn{5}{|c|}{ Regulation of signalling } \\
\hline $\operatorname{Lrg} 1$ & Leucine-rich alpha-2-glycoprotein 1 & 2.30 & 2.26 & 2.27 \\
\hline Tcl1b3 & T-cell leukemia/lymphoma 1B, 3 & 2.61 & 1.80 & 2.10 \\
\hline Tifa & TRAF-interacting protein with forkhead-associated domain & 1.86 & 3.52 & 15.81 \\
\hline Tspan4 & Tetraspanin 4 & 1.68 & 1.92 & 1.68 \\
\hline \multicolumn{5}{|c|}{ Binding activity } \\
\hline Cpne8 & Copine VIII & 3.44 & 2.48 & 6.19 \\
\hline Dnajc12 & DnaJ (Hsp40) homolog, subfamily C, member 12 & 3.29 & 2.70 & 2.09 \\
\hline Ifitm6 & Interferon induced transmembrane protein 6 & 3.36 & 1.69 & 2.94 \\
\hline Mpeg1 & Macrophage expressed gene 1 & 2.37 & 1.56 & 1.70 \\
\hline Rpap3 & RNA polymerase II associated protein 3 & 2.59 & 1.69 & 2.45 \\
\hline Serpina10 & $\begin{array}{l}\text { Serine (or cysteine) peptidase inhibitor, clade A (alpha-1 antiproteinase, } \\
\text { antitrypsin), member } 10\end{array}$ & 1.95 & 1.91 & 3.05 \\
\hline Snx10 & Sorting nexin 10 & 1.78 & 1.95 & 2.50 \\
\hline Tmem176a & Transmembrane protein 176A & 1.79 & 1.52 & 2.21 \\
\hline \multicolumn{5}{|c|}{ Cellular development and differentiation } \\
\hline Fndc3b & Fibronectin type III domain containing 3B & 2.99 & 2.04 & 2.28 \\
\hline
\end{tabular}

Mice were treated with $30 \mathrm{mg} / \mathrm{kg}$ diclofenac once daily for up to 14 days. Whole genome microarray studies were performed and analyzed as detailed in the Material and Method section. 74 statistically significantly regulated genes $(p<0.01)$ were in common when single and repeated treatment groups were compared.

*The marked genes are also involved in stress response. 
A.1

DCF_Day 1_DEGs (471) DCF_Day 3_DEGs (564)

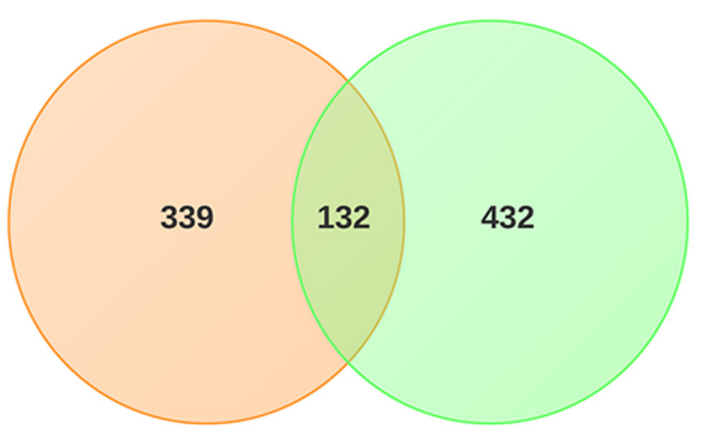

\section{A.2}

DCF_Day 1_DEGs (471) DCF_Day 3_DEGs (564)

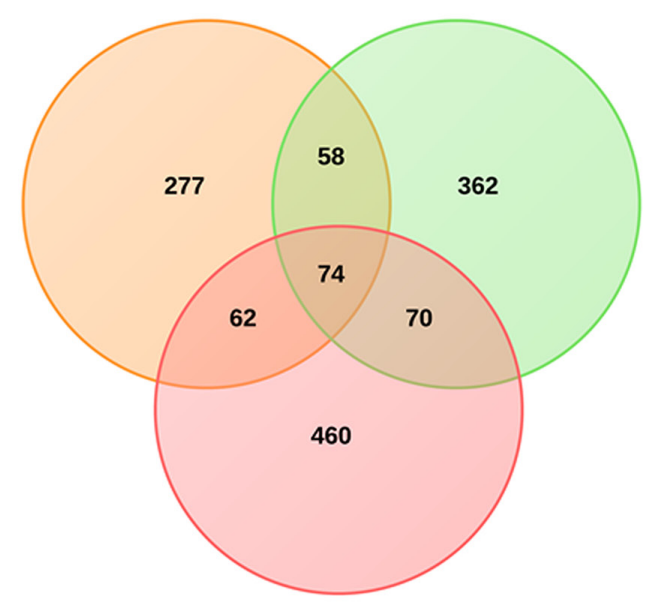

DCF_Day14_DEGs (666)
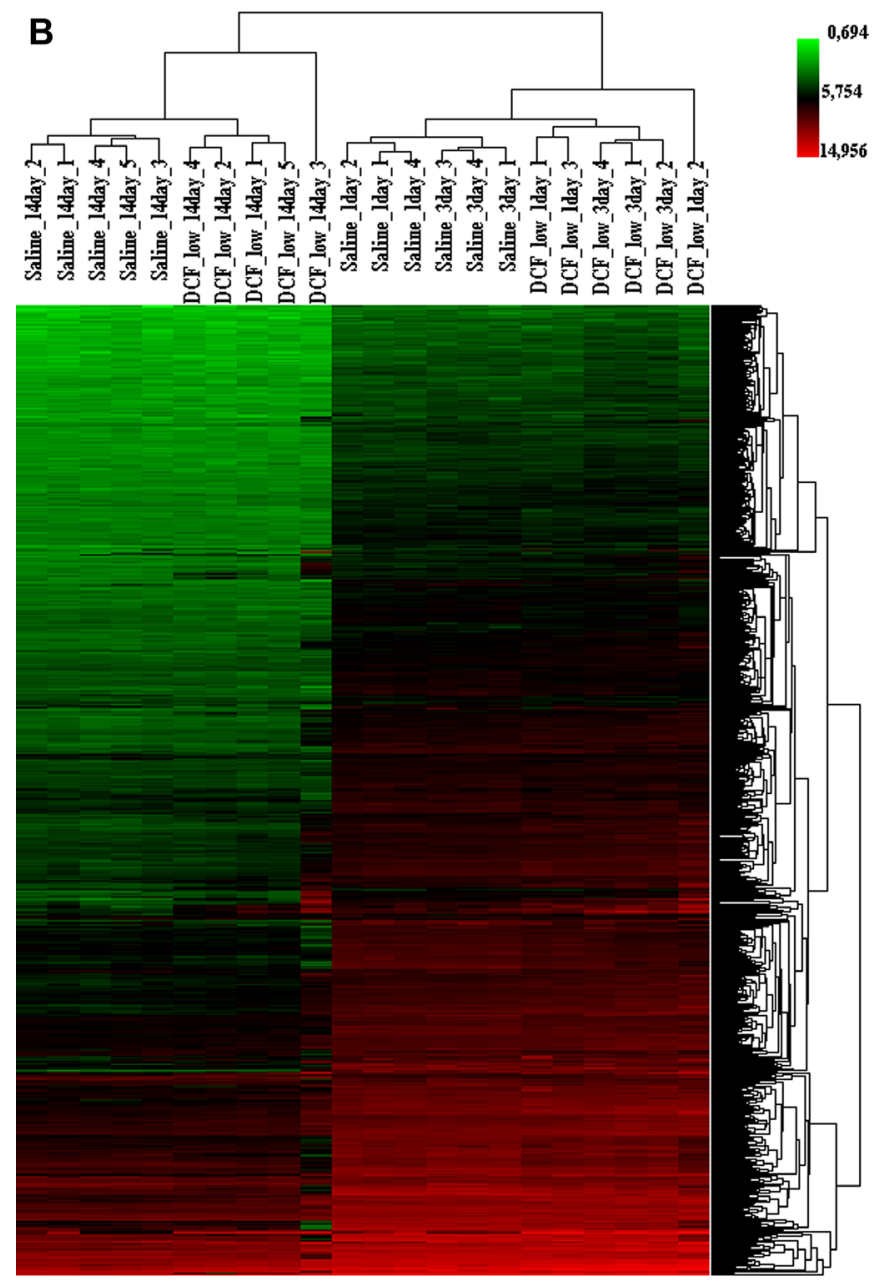

Figure 10: (A) Differentially expressed genes after single and repeated diclofenac treatment in mice. Venn diagrams of DEGs induced after single (day 1) and repeated (day 3 and day 14) treatment. A total of 132 genes were found to be regulated in common after single and repeated treatment for 3 day. Furthermore, 74 genes were commonly regulated amongst all treatment groups. (B) Heat map of differentially expressed genes in liver of diclofenac treated mice. The heat map was generated using average-linkage hierarchical clustering with Euclidean distance. The heat map was generated with the ArrayTrack software version 3.5.0. Depicted is the signal intensity value for differentially expressed genes. The diclofenac day 1,3 and 14 treatment group were clearly segregated from the vehicle treated control animals. 
Table 3: Master regulator genes after single and repeated diclofenac treatment for 14 days

\begin{tabular}{|c|c|c|c|c|c|c|c|}
\hline \multirow[b]{2}{*}{ Master regulatory genes } & \multicolumn{2}{|c|}{ No of genes } & \multirow[b]{2}{*}{ Score } & \multirow[b]{2}{*}{ FDR } & \multirow[b]{2}{*}{$Z$-score } & \multirow{2}{*}{$\begin{array}{l}\text { Average } \\
\text { Fold } \\
\text { change }\end{array}$} & \multirow[b]{2}{*}{$\begin{array}{c}\text { Rank } \\
\text { sum }\end{array}$} \\
\hline & $\begin{array}{l}\text { Total No of } \\
\text { genes in } \\
\text { the network }\end{array}$ & $\begin{array}{l}\text { Statistically } \\
\text { significant } \\
\text { DEGs }\end{array}$ & & & & & \\
\hline \multicolumn{8}{|l|}{ After single dose (day 1 ) } \\
\hline Leptin receptor (Lepr) & 248 & 142 & 0.47394 & 0.011 & 2.54686 & 1.91 & 15 \\
\hline $\begin{array}{l}\text { Growth hormone receptor } \\
\text { (Ghr) }\end{array}$ & 247 & 140 & 0.42311 & 0.018 & 2.88692 & -1.48 & 18 \\
\hline $\begin{array}{l}\text { Protein tyrosine phosphatase, } \\
\text { non-receptor type } 2 \text { (Ptpn } 2)\end{array}$ & 253 & 146 & 0.42122 & 0.029 & 2.22294 & 1.57 & 27 \\
\hline \multicolumn{8}{|c|}{ After repeated treatment (day 3 ) } \\
\hline Leptin receptor (Lepr) & 254 & 145 & 0.44159 & 0.047 & 1.88705 & -1.66 & 14 \\
\hline $\begin{array}{l}\text { Selectin, endothelial cell } \\
\text { (Sele) }\end{array}$ & 262 & 153 & 0.44818 & 0.05 & 1.95103 & 1.61 & 12 \\
\hline $\begin{array}{l}\text { Suppressor of cytokine signal- } \\
\text { lingsignaling } 3 \text { (Socs } 3)\end{array}$ & 287 & 158 & 0.59558 & 0.019 & 1.78924 & 3.43 & 11 \\
\hline \multicolumn{8}{|c|}{ Common DEGs after single (day 1 ) and repeated treatment (day 3 ) } \\
\hline Leptin receptor (Lepr) & 68 & 33 & 0.62653 & 0.001 & 1.93479 & & 17 \\
\hline Lipocalin 2 (Lcn2) & 78 & 34 & 0.44549 & 0.015 & 1.96325 & 22.62 & 42 \\
\hline $\begin{array}{l}\text { Nuclear factor of kappa light } \\
\text { polypeptide gene enhancer in } \\
\text { B cells inhibitor, zeta (Nfkbiz) }\end{array}$ & 70 & 34 & 0.4655 & 0.006 & 2.13014 & 2.91 & 31 \\
\hline \multicolumn{8}{|c|}{ After repeated treatment (day 14) } \\
\hline $\begin{array}{l}\text { Serum amyloid P-component } \\
\text { (Apcs) }\end{array}$ & 144 & 88 & 0.43611 & 0.047 & 1.76832 & 6.77 & 2 \\
\hline $\begin{array}{l}\text { Cytotoxic T-lymphocyte-asso- } \\
\text { ciated protein } 4 \text { (Ctla4) }\end{array}$ & 161 & 94 & 0.55188 & 0.048 & 1.28056 & 2.17 & 3 \\
\hline CD44 antigen (Cd44) & 172 & 96 & 0.6616 & 0.046 & 1.18176 & 1.77 & 3 \\
\hline
\end{tabular}

Given is a summary of master regulatory networks with the number of total interacting genes and DEGs within the constructed networks, network score, $Z$-score and average fold change.

Note: $Z$ - Score $>1$ and Score $>0.2$ was set to select statistically significant master regulators.

(see Table S2). Specifically, Cxcl1, Cxcl2, and Cxcl13 facilitate recruitment of neutrophils, leukocytes, and B lymphocytes to sites of injury whereas $\mathrm{Xcll}$ and $\mathrm{Ccl} 6$ support differentiation of myeloid cells and $\mathrm{CD}^{+} \mathrm{T}$ cells $[20,21]$. Increased expression of $\mathrm{Il}-7$ by hepatocytes controls $\mathrm{T}$ cell responses [21] while $I l-15$ regulates the activation and proliferation of $\mathrm{T}$ cells and natural killer
(NK) cells [22]. Additionally, $I l-33$ was up-regulated and this member of the $I l-1$ superfamily stimulates production of type 2 cytokines by T helper cells [23]. Thus, diclofenac treatment resulted in an increased expression of cytokines to influence $\mathrm{T}$ cell differentiation. According to the danger hypothesis, a danger signal is induced by immune responses to antigens as well as the interaction of pro- 
A

Day 1

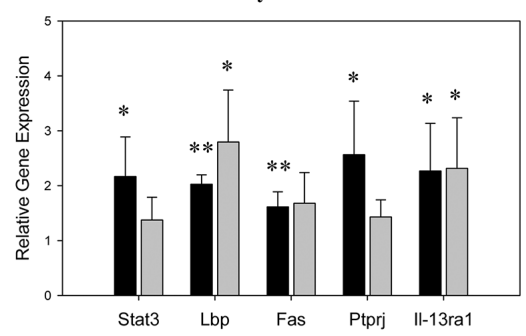

B

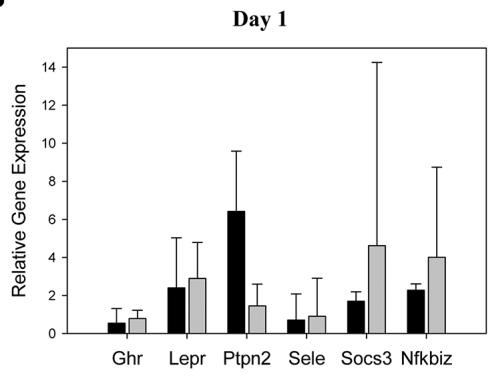

Day 14

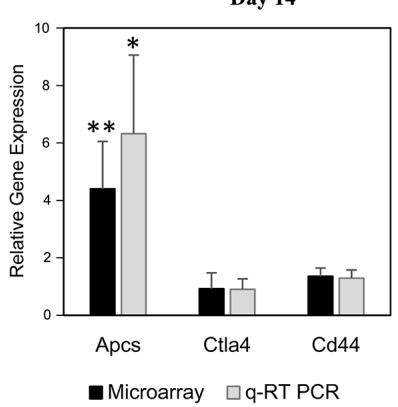

C

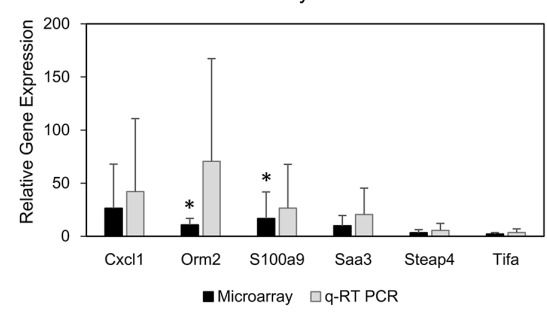

Day 14

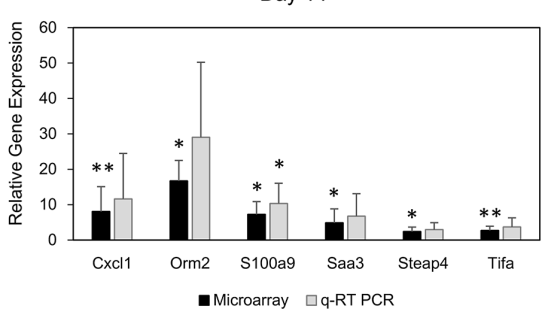

Day 3

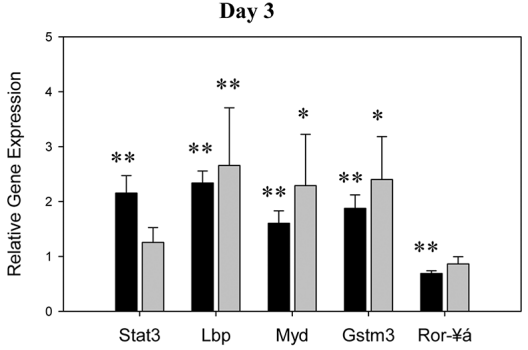

Day 3

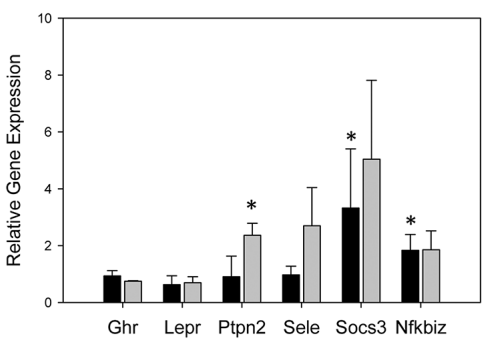

Len2

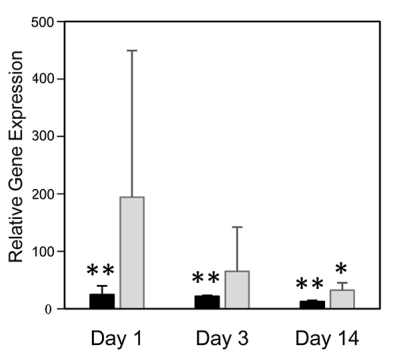

- Microarray $\quad \square \mathrm{q}-\mathrm{RT} P C \mathrm{P}$

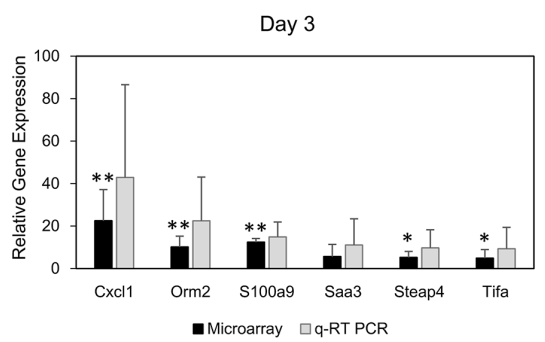

Figure 11: Microarray data validation by real time quantitative PCR. (A) Validation of microarray data by quantitative realtime PCR of randomly selected genes. The $y$-axis indicates the relative fold change in expression (diclofenac-treated $v s$. saline-treated controls). Data are means $\pm \mathrm{SD}(n=3)$. ${ }^{*} P<0.05,{ }^{*} P<0.01$. (B) Validation of master regulators by quantitative real-time PCR. The $y$-axis indicates the relative fold change in expression (diclofenac-treated $v s$. controls). Data are means $\pm \operatorname{SD}(n=3) . * P<0.05, * * P<0.01$. (C) Validation of cytokines by quantitative real-time PCR. The $y$-axis indicates the relative fold change in expression (diclofenac-treated vs. controls). Data are means $\pm \mathrm{SD}(n=3) .{ }^{*} P<0.05,{ }^{*} P<0.01$. 
inflammatory cytokines and polarizing cytokines [24] and in the case of diclofenac involved regulation of Tlr2, Tlr13 and the apoptosis related genes Fas, Tnfrsfla, Myd88, and Nfkbiz. The Chi3l3 gene was highly expressed, and this protein is known to be released from macrophages during inflammation. Diclofenac also induced S100a8 and S100a9 transcript expression and increased levels of the proteins hallmark numerous pathological conditions associated with inflammation [25].

Furthermore, the expression of acute phase response genes was up-regulated in response to diclofenac treatment. Acute phase proteins are produced by hepatocytes and controlled by cytokines such as $I l-1 \beta$, Tnf- $\alpha$, Ifn $\gamma$, and Il-6 [26]. According to the study of Yano et al., 2012 [10] expression of $\mathrm{Il}-1$ is highest at $3 \mathrm{~h}$, but expression of $\operatorname{Tn} f-\alpha$ peaked at $24 \mathrm{~h}$ in diclofenac-treated mouse liver (80 mg/kg, i.p.) [11].

Additionally, Stat3 is known to be a transcription factor activated by cytokines and growth factors and plays a key role in many cellular processes such as cell growth and apoptosis. In hepatocytes, Stat3 is directly involved in the transcription of acute phase proteins by stimulating Il-6 and interaction with Nfkb1 [26]. In the present study, phosphorylated Stat3 was highly induced in some of the treated animals (see Figure 12) and this protein controls transcription of Socs 3 which functions as an inhibitor of Jak/Stat3 signalling [27]. Notably, Socs 3 supports differentiation of the Th17 and is implicated in autoimmune disease and a recent study reported that the expression of Th17 cell-mediated factors such as $R O R-\gamma \mathrm{t}$, and Stat3 increased significantly in diclofenac-treated mouse liver [10].

Taken collectively, the release of proinflammatory cytokines by diclofenac stimulates cytokine receptor activation. Moreover, Stat3, which is activated by cytokine signalling, induces expression of acute phase proteins and differentiation of $\mathrm{T}$ cells and this feedback-loop is controlled by Socs3 [28]. Expression of Il4ra and IL13ral was also increased in response to diclofenac treatment; the
A

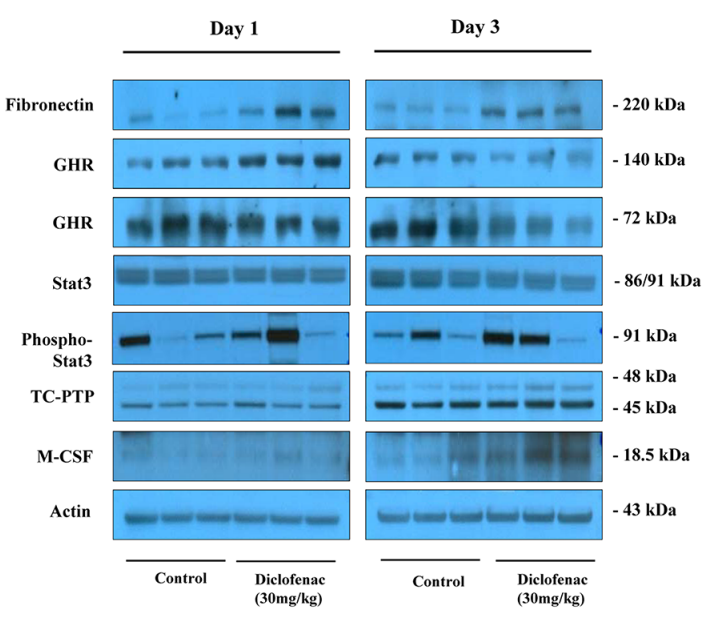

B
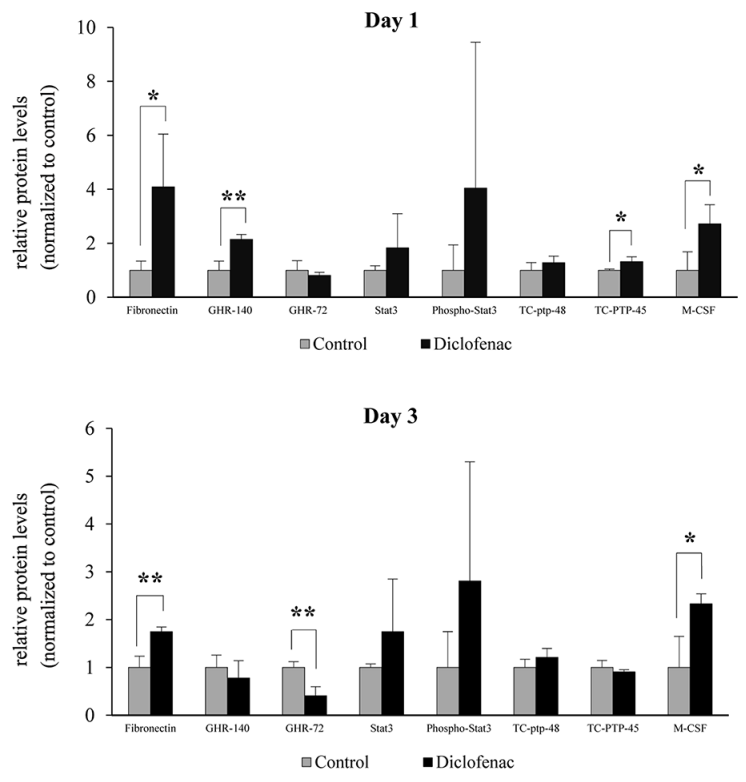

C

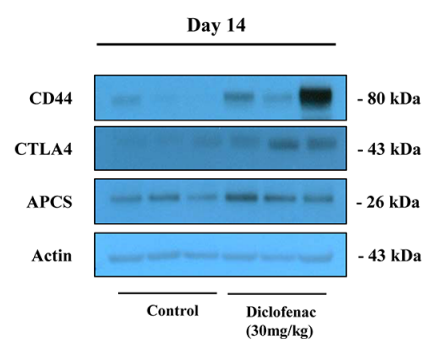

CD44

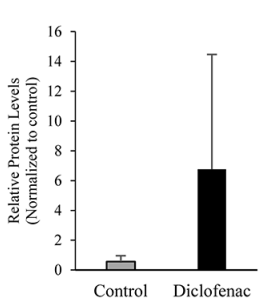

Day 14

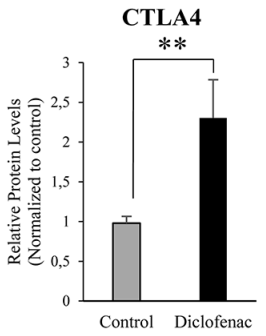

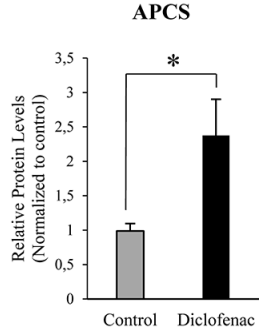

Figure 12: Western blotting of master regulatory proteins in liver extracts of diclofenac treated mice. Depicted is the expression of master regulators after single and repeated treatment of mice for up to 14 days. (A and C) depict the Western immunoblotting results; the histograms in $(\mathbf{B})$ represents densitometric scans of the immunoblots relative to the vehicle control. Data are expressed as mean and standard deviation. ${ }^{*} P<0.05, * * P<0.01$. 

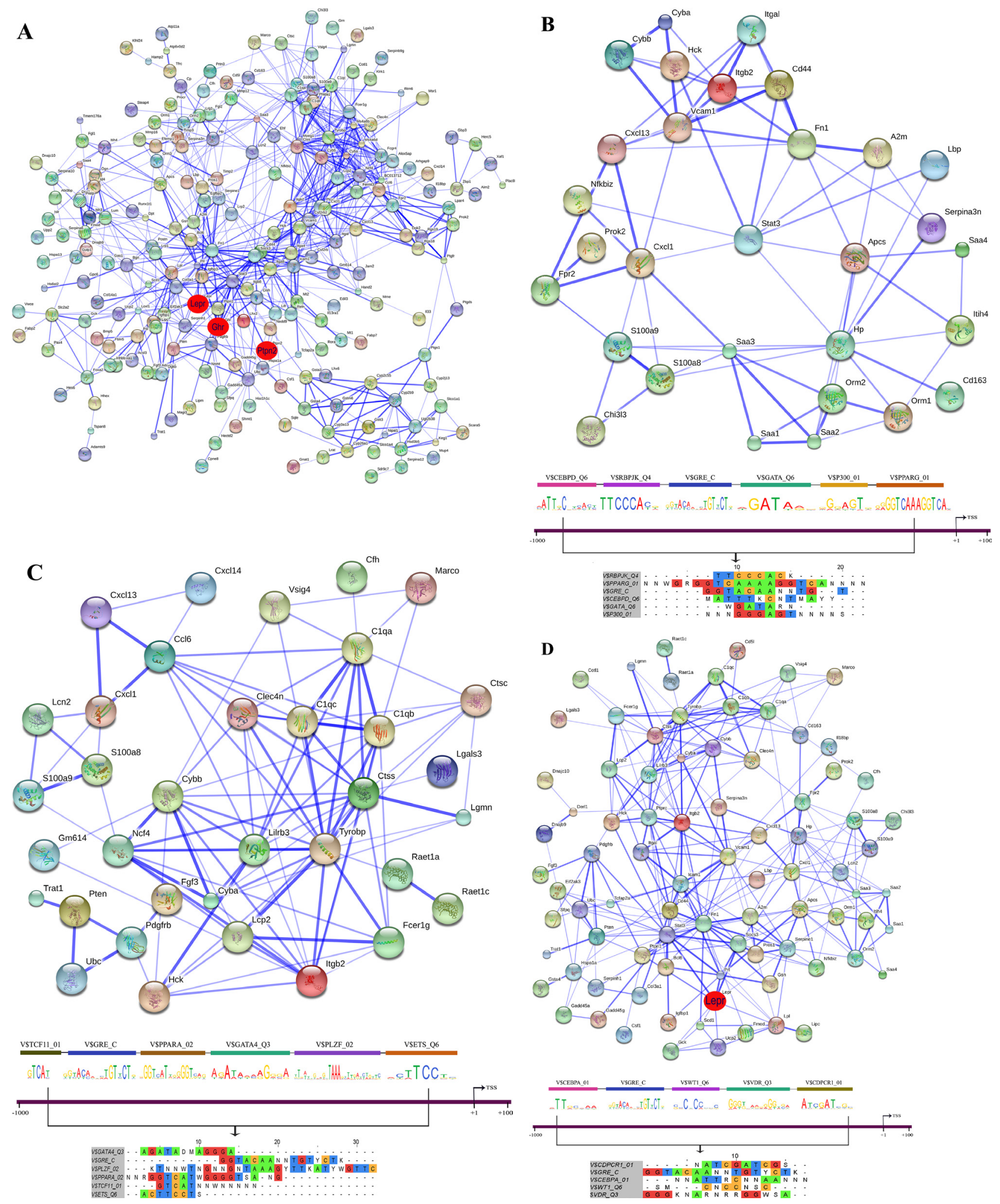

Figure 13: String protein interaction network and composite modules in livers of diclofenac treated mice after single treatment. (A) Out of 471 DEGs a protein interaction network was constructed that consists of 225 DEGs and involved 749 PPIs. The red circle highlights the master regulatory genes; the strength of association amongst individual proteins is illustrated with the thickness of the blue line as defined in the STRING version 9.1. (B) Inflammatory response sub-network with its composite module of co-bound transcription factors at promoters of regulated genes. (C) Immune response sub-network with its composite module of co-bound transcription factors at promoters of regulated genes. (D) Stress response network with its composite module of co-bound transcription factors at promoters of regulated genes. 

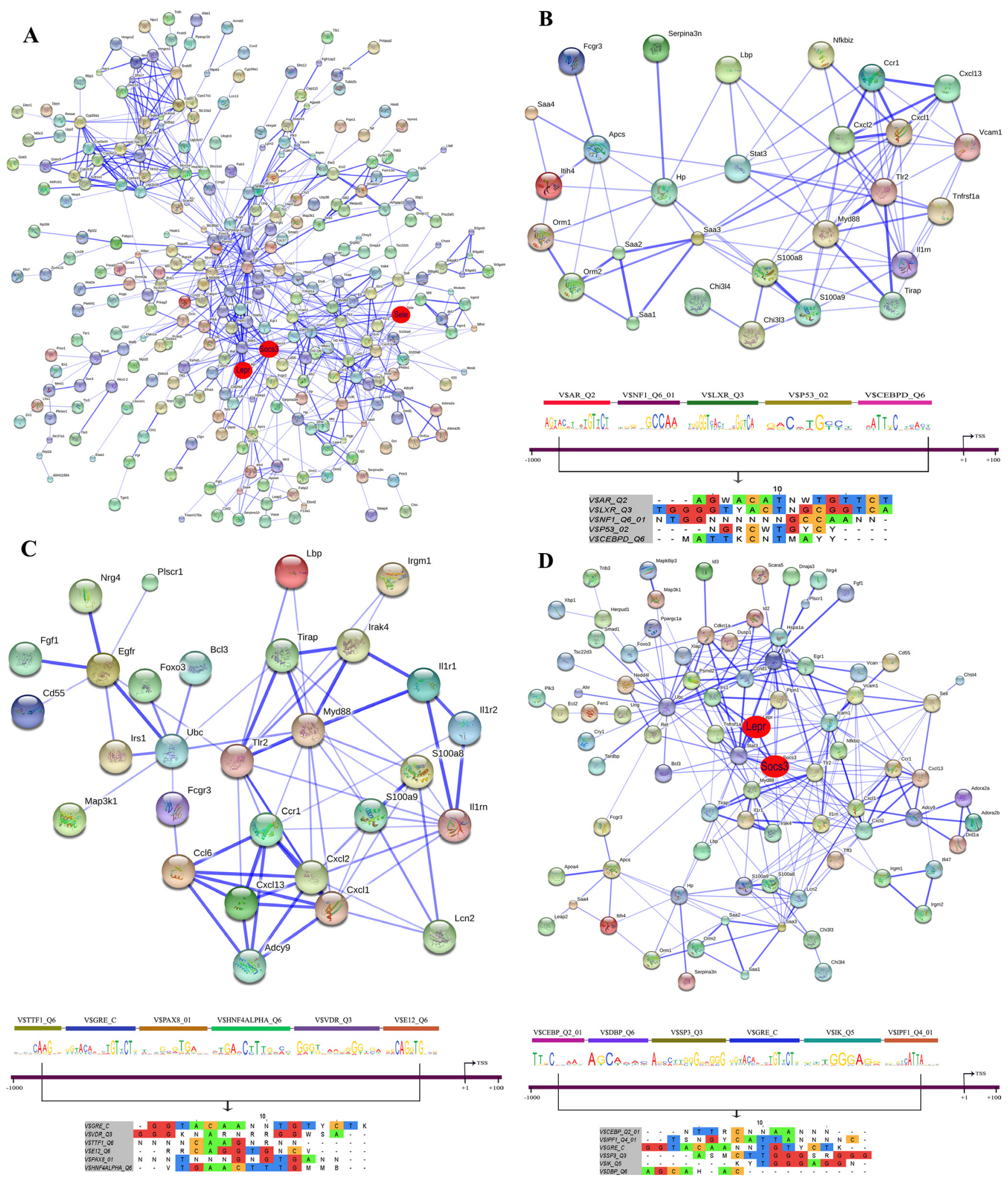

Figure 14: String protein interaction network and composite modules in livers of diclofenac treated mice after repeated treatment for 3 days. (A) Out of 564 DEGs a protein interaction network was constructed that consisted of 277 DEGs and involved 687 PPIs. (B) Inflammatory response sub-network and its composite module. (C) Immune response sub-network and its composite module. (D) Stress response sub-network and its composite module. Please see Figure 13 for a description of the inferred association defined by the STRING version 9.1. 

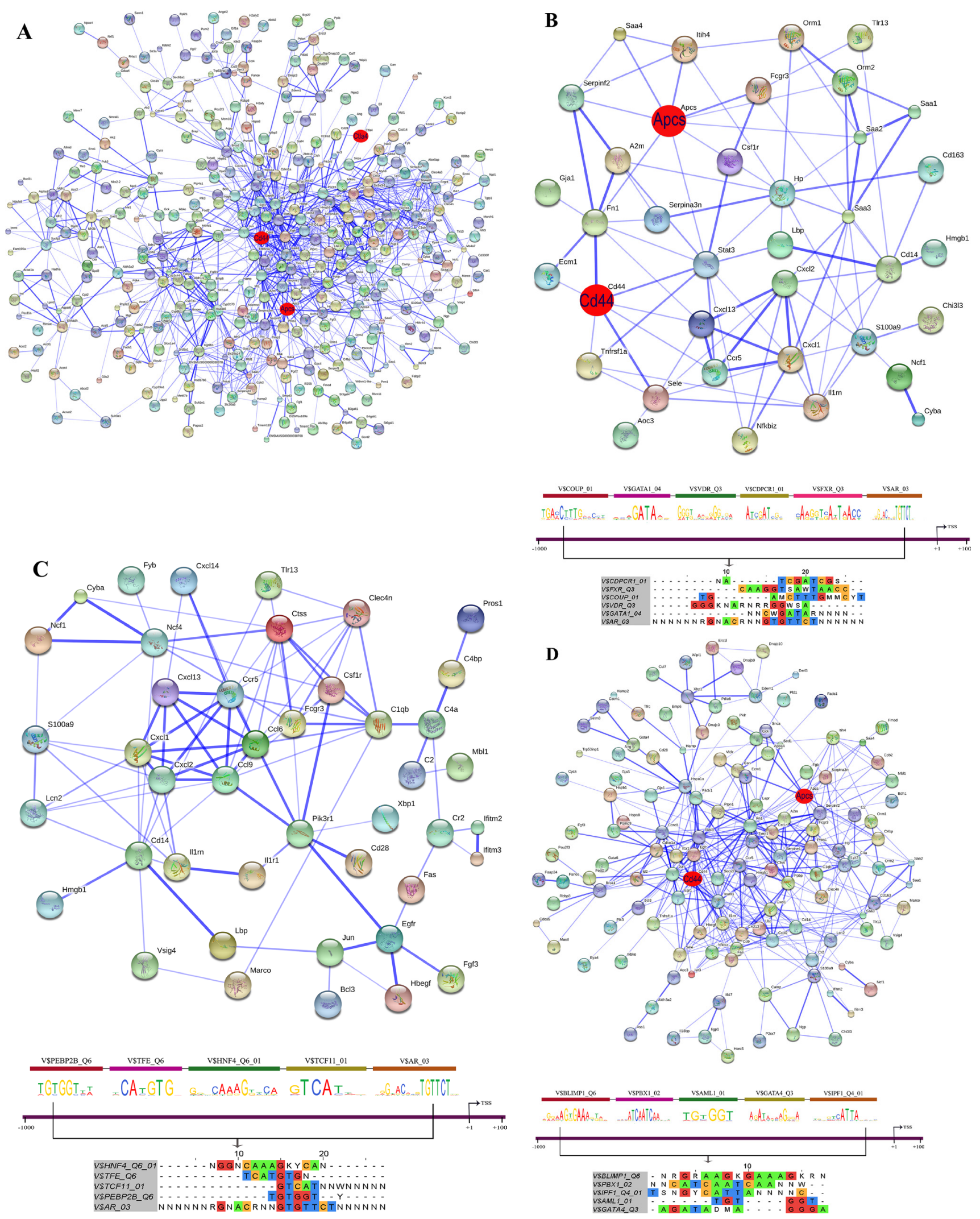

Figure 15: String protein interaction network and composite modules in livers of diclofenac treated mice after repeated treatment for 14 days. (A) Out of 666 DEGs a protein interaction network was constructed that consists of 348 DEGs and involved 1043 PPI. (B) Inflammatory response sub-network and its composite module. (C) Immune response sub-network and its composite module. (D) Stress response sub-network and its composite module. Please see Figure 13 for a description of the inferred association defined by the STRING version 9.1. 
coded proteins are known to activate Jak/Stat6 signalling through binding of $\mathrm{Il}-4$ and $\mathrm{Il}-13$ [29]. Therefore, the Jak/ Stat, PPAR, adipocytokine and chemokine signalling pathways were significantly influenced after single and repeated diclofenac treatment.

\section{Molecular circuits of inflammation}

The network analysis defined several master regulators, i.e. the leptin receptor, Ghr, Ptpn2, Socs3, Sele, Lcn2, Nfkbiz, Ctla4, Apcs and Cd44 after single and repeated diclofenac treatment. Four of the master regulators (Lepr Ghr, Ptpn2 and Socs3) directly interact with Stat 3 to significantly influence the constructed gene networks. As described above, Stat3 is rapidly activated by various cytokines and growth factors including $\mathrm{Il}-6$, EGF family members and hepatocyte growth factor as part of an immune response and inflammation [30-32]. This factor intercede regulation of several pro-inflammatory (Mapks, p38, Jnk, and $I \kappa B$ kinase) and anti-inflammatory (Pi3k-Akt) signalling cascades as had been observed in LPS treated mice $[25,33]$. Another factor significantly up-regulated in response to diclofenac treatment was leptin and this $16-\mathrm{kDa}$ adipokine plays a key role in energy intake to influence monocyte/ macrophagemediated responses during inflammation [34]. Several studies suggest leptin to be a pro-inflammatory molecule whereby the leptin receptor directly or indirectly modulates signalling pathways involved in kinaseinduced phosphorylation by Jak2/Stat3, Erbb2, Erk, Irsl and Rho/Rac [35]. This cytokine interacts with Socs3, i.e. another master regulator of the repeated diclofenac treatment network; its interaction with Stat 3 constitutes a negative feedback loop on leptin receptor activity [36, 37]. Several of the pro-inflammatory cytokines found to be upregulated in the present study also induce expression of Socs 3 and this protein is an important master regulator that can be activated by STAT and nuclear factor $\kappa \mathrm{B}(\mathrm{NF} \kappa \mathrm{B})$ mediated pathways [38].

The growth hormone receptor is another master regulator identified in the network analysis and plays a major role in response to tissue injury [39, 40]. Importantly, the growth hormone and leptin receptors are influenced by multiple intracellular signalling cascades, including Jak-Stat pathway [41] and chemokine signalling pathway found to be regulated in the present study (Hck, Ncf1, Stat3, Nfkb1, and Cxcl1) and are a part of the hepatic inflammatory response [42] to suppress hepatic $G h r$ signalling [43]. Specifically, GHR protein expression was reduced at day 3 of diclofenac treatment thus evidencing its degradation (see Figure 12).

Additionally, the protein tyrosine phosphatase (Ptpn2) was identified as a master regulator and it's regulation by diclofenac is of particular importance in the modulation of interferon gamma signal transduction as part of the inflammatory pathway [44]. In the present study
Tc-PTP was modestly but significantly up-regulated as determined by qRT-PCR and immunoblotting. The present study also identified E-selectin as a master regulator whose decisive roles in placing leukocytes to the site of injury during inflammation has been documented [45]. The increased expression of Lcn2 is of clinical significance and is associated with activation of neutrophils as seen in inflammation and oxidative stress conditions [46]. It is also strongly induced in hepatocytes and adipocytes, both in vitro and in vivo by pro-inflammatory cytokines, such as interleukin-1ß and tumour necrosis factor alpha and was induced by diclofenac treatment [47].

Network analysis of 14 day repeated diclofenac treatment data revealed the cytotoxic $\mathrm{T}$ lymphocyteassociated antigen 4 (Ctla4) as master regulator; note, the coded protein is a key element in the immune system to induce immune tolerance and is one of the critical negative regulators of the $\mathrm{T}$ cell-mediated immune response. Furthermore, Ctla4 gene polymorphism is a risk factor for drug induced liver injury [48] and is associated with autoimmune liver diseases including primary biliary cirrhosis [49]. Ctla4-mediated signal transduction was also reported to induce cell death in previously activated $\mathrm{T}$ cells and abnormal expression of Ctla 4 can be associated with varies pathologies including chronic immune diseases as well as malignancies [50]. Likewise, the serum amyloid P-component (Sap or Apcs) is a major acute phase protein that is synthesized in response to pro-inflammatory cytokines and binds to DNA to modulate immune responses [51]. It was reported that hepatic Apcs gene expression is enhanced during inflammation [52, 53].

Lastly, network analysis revealed $C d 44$ as a master regulator which we found highly but variably regulated amongst individual animals (Figure 12). This membrane bound receptor functions in the regulation of several biological processes including adhesion, migration, invasion, survival and inflammation [54] and plays a role in a variety of inflammatory responses, including the induction of proinflammatory cytokines and the migration of macrophages and neutrophils $[55,56]$. Binding of hyaluronic acid to $C d 44$ promotes the interaction with a number of other cell surface proteins, for instance Tlr4 and Egfr, and influences the activity of a variety of downstream protein kinase signalling pathways (MAP kinase and Akt pathways) [57]. It was also reported that $C d 44$ provides a critical link between cellular metabolic changes and the development of inflammation as well as insulin resistance in liver [58].

\section{Co-occupancy of transcription factor binding sites}

Regulatory gene networks were interrogated by analysing transcription factor binding sites at gene specific promoters. Eventually, composite modules were computed after single and repeated treatments. A notable 
finding is the vitamin D receptor $(V d r)$, i.e. a transcription factor that was significantly regulated in either composite module after single and repeated diclofenac treatment regimens. Several independent studies implicate $V d r$ in the inflammatory response [59-61] and in the innate and adaptive immune system [62-64] by regulating the production of inflammatory cytokines and inhibiting the proliferation of pro-inflammatory cells, both of which are crucial for the pathogenesis of inflammatory and autoimmune diseases. Moreover, $V d r$ polymorphisms are associated with risk and severity of liver diseases such as primary biliary cirrhosis, autoimmune hepatitis and hepatocellular carcinoma $[65,66]$.

Besides, the transcription factor and master regulator glucocorticoid receptor $(\mathrm{Nr} 3 \mathrm{cl})$ is strongly implicated in the regulation of inflammatory, immune and stress response genes after single and repeated diclofenac treatment with most of the inflammatory response genes being bona fide targets for Gre and $N f k b[67,68]$.

Furthermore, the CCAAT/enhancer-binder protein (C/EBP) families of transcription factors (i.e. Cebpd and Cebpa) play an important role in the transcriptional regulation of inflammatory and stress response genes [69]; thus a complex interplay exists by which Tnfalpha, Il-1, nuclear factor $\kappa \mathrm{B}$, activator protein-1, early growth response protein-1 and C/EBPs to intensify the inflammatory response [70] with Cebpß and $\mathrm{d}$ isoforms being up-regulated while Cebpa was down regulated in response to inflammation [33]. The co-occupancy TF analysis also revealed GATA factors to take part in the inflammatory and stress response after single and repeated diclofenac treatment. Among the GATA Zn-finger proteins isoforms 1 to 3 play major roles in the hematopoietic and immune system [71] whereas Gata4 and Gata6 participate in the control of liver-specific gene expression as was shown by Mwinyi et al., 2010 [72]. It was reported that Gata2 and 3 engage in protein complexes with Cebpa/ Cebp $\beta$ to jointly suppress adipocyte differentiation [73]. In addition, the liver-specific transcription factors Hnfla and $H n f 4 a$ are part of the constructed inflammatory and immune composite modules and play a crucial role in the regulation of metabolism including bile acid, cholesterol and lipoprotein metabolism as well as glucose and fatty acid metabolism by maintaining hepatocyte differentiation [74-76]. During inflammation the metabolic competence of the liver is greatly affected and involves altered nuclear receptor activity, cross-talk amongst different cell types including macrophages, B and T cells, cytokine signalling and cytokine mediated activity of liver enriched transcription factors to influence liver regeneration, apoptosis, and liver-specific gene regulation as had been reviewed by us [74, 77, 78].

Moreover, repeated diclofenac treatment elicited regulation of the $P 53$ tumour suppressor. This transcription factor is activated in response to different cellular stresses including DNA damage and hypoxia and mediates a variety of anti-proliferative processes [79]. The interaction of p53 with the transcription co-activators p300 (see Figure 14B) and CREB-binding protein (CBP) enhances its ability to bind and activate transcription of target genes [80]. Likewise, Ppar is a part of the composite module constructed after single diclofenac treatment and the Ppar family transcription factors can be activated by numerous fatty-acid metabolites that are produced during the inflammatory response. In vivo and in vitro studies evidence PPAR signalling pathway to be significantly regulated in diclofenac treated mice [81] and Ppary is involved in negative regulation of $\mathrm{Il}-6$ mediated acute phase response in hepatocytes. The transcription factors Ppary and Cebpa are both inferred in the stress and inflammatory response composite modules after single diclofenac treatment and are known to promote adipocyte differentiation [82] with Ppary regulating the expression of a number of genes involved in peroxisomal and mitochondrial fatty acid $\beta$-oxidation. Similarly, Lxr has been characterized as regulator of macrophage inflammatory pathways and is a part of the constructed inflammatory response composite module after repeated diclofenac treatment for day 3.

Therefore, coordinate regulations of Ppar and Lxr transcription factors and glucocorticoid receptor have been proposed to integrate local and systemic responses to inflammation $[83,84]$. Recent studies also highlight the role of chromatin higher order structure in the regulation of inflammatory gene expression and specifically the p300 co-activator protein. This histone acetylase functions through various interaction domains such as the RID, KIX, the interferon response binding domain and p53 with transcription factors defined in the inflammatory and immune response networks (see Figure 14B). A further member of the constructed composite module is $R b p-j$, i.e. a DNA binding protein that plays a key role in signal transduction during myeloid cell differentiation by the Notch signalling pathway $[85,86]$.

The farnesoid $\mathrm{X}$ receptor $(F x r)$ was regulated by diclofenac and apart from its role in bile acid homeostasis it also functions in triglycerides, cholesterol and carbohydrate metabolism during the acute phase response [87]. It was shown earlier that pro-inflammatory cytokines induce Fxr activity during infection and inflammation, accompanied by abnormalities in lipid metabolism that are similar to those seen in common disorders, such as diabetes, obesity, and the metabolic syndrome [88, 89].

A further transcription factor of the inflammatory and immune response composite module with eminent importance in liver biology is the androgen receptor $(A r)$; altered $A r$ signalling is observed in various liver diseases including steatosis, cirrhosis and hepatocellular carcinoma [90] and was shown to play a suppressive role on liver gene expression during inflammation. In addition, 
exaggerated $\mathrm{Ar}$ activity may promote hepatocarcinogenesis via increased cellular oxidative stress, DNA damage/ repair and cell apoptosis [91, 92].

Lastly, our network analysis of diclofenac induced immune response genes inferred regulation of the Tcf11/ Nrfl transcription factor and the protein is known to influence expression of genes involved in glutathione (GSH) biosynthesis and other oxidative defence enzymes. Importantly, knockout of the gene in the liver of mice caused increased inflammation, apoptosis and spontaneous development of hepatic cancer [93]. The transcription factor $T f e 3$ is part of day 14 immune response composite module and plays a major role in activation of the immune system [94] and the regulation of glucose metabolism in liver [95].

\section{CONCLUSIONS}

The present study provides evidence for a mechanism of diclofenac induced liver injury that involves pro-inflammatory cytokine and acute phase responses. We propose a molecular circuit that lead to an imbalance of pro- and anti-inflammatory signalling as a cause of what is supposed to be an idiosyncratic liver injury. The methodology employed in the present study may also help to understand immune allergic liver injury induced by other NSAIDS.

\section{METHODS}

\section{Animals and drug treatment}

All animal work followed strictly the Public Health Service (PHS) Policy on Humane Care and Use of Laboratory Animals of the National Institutes of Health, USA. Formal approval to carry out animal studies was granted by the animal welfare ethics committee of Institutional Animal care and Use Committee (IACUC).

C57BL6- mice (males, 8 weeks old) were purchased from the Orient-Bio Co. (Seongnam, Korea). Mice were maintained under laboratory conditions of controlled temperature $\left(23 \pm 3^{\circ} \mathrm{C}\right)$ and humidity $(55 \pm 10 \%)$ with a 12/12 h light/dark cycle and were given standard food pellets and water ad libitum. The sodium salt of diclofenac was purchased from (Sigma-Aldrich, St. Louis, MO) and diluted in sterile saline (Sigma-Aldrich) and administered daily by intraperitoneal injection of $30 \mathrm{mg} / \mathrm{kg}$ (low dose, $N=6$ ) or $150 \mathrm{mg} / \mathrm{kg}$ (high dose, $N=6$ ) for up to 14 days. Because of the high mortality observed at the $150 \mathrm{mg} / \mathrm{kg}$ dose the genomic studies were performed with tissue samples of the lower dose only. Control mice $(N=6)$ were administered corresponding quantities of saline. The mice were killed at $24 \mathrm{~h}$ (day 1), $72 \mathrm{~h}$ (day 3) or 14 days after vehicle or diclofenac administration. Furthermore, studies with primary mouse collagen sandwiched hepatocytes were performed using a protocol previously described $[96,97]$ with the following modifications: Briefly, the portal vein of $N=3$ mice was cannulated with a 22-gauge plastic cannula and the liver was perfused with a Krebs Ringer buffer ( $\mathrm{pH} 7.4)$ containing glucose (10 mM) and Hepes $(10 \mathrm{mM})$, at a flow rate of $4 \mathrm{ml} / \mathrm{min}$. The liver was subsequently perfused with a collagenase solution (Calcium containing Krebs Ringer Buffer with glucose) for 10-15 $\mathrm{min}$. Hepatocytes were isolated by removing the capsule and filtering through the cell strainer. Isolated hepatocytes were washed three times with ice cold DMEM containing $10 \%$ FBS and hepatocytes of $>90 \%$ viability were obtained by using the Optiprep ${ }^{\mathrm{TM}}$ density gradient medium (Sigma-Aldrich, St. Louis, MO). The primary hepatocytes were suspended in DMEM medium (Lonza, Verviers, Belgium) and plated on collagen coated dishes. After four hours the medium was discarded and overlaid with a sandwich matrix $\left(1.25 \mu \mathrm{g} / \mathrm{cm}^{2}\right.$ of rat tail collagen $)$. The medium was replaced with fresh HepatoZYME-SFM (Life technologies) medium and after 24 hours of culture primary hepatocytes were treated with $500 \mu \mathrm{M}$ diclofenac for a further $24 \mathrm{~h}$. The control group was treated with the vehicle only $(0.5 \% \mathrm{v} / \mathrm{v}$ DMSO $)$.

\section{Blood biochemistry}

Blood was drawn from the inferior vena cava, and serum was obtained by centrifugation at 3,000 rpm for $30 \mathrm{~min}$ at room temperature. Serum aspartate aminotransferase (AST), alanine aminotransferase (ALT), alkaline phosphatase (ALP) and total bilirubin (TBIL) were measured using a Dry Chem-3000 autoanalyzer (FujiFilm, Tokyo, Japan).

\section{RNA extraction}

The liver was explanted from the diclofenac (30 mg/kg) and saline-treated mice, washed free of blood and snap-frozen in liquid nitrogen. Liver samples were subsequently stored in a deep freezer until RNA extraction. Frozen liver samples were immediately added to the RLT buffer containing $\beta$-mercaptoethanol and homogenized using a TissueLyser (Qiagen, Hilden, Germany). Total RNA from each tissue was isolated and purified using the RNase mini kit (Qiagen) according to the manufacturer's recommendation. The concentration of total RNA was assessed using a NanoDrop spectrophotometer (NanoDrop Technologies, Wilmington, DE), and RNA integrity was determined with a 2100 Bioanalyzer (Agilent Technologies, Santa Clara, CA).

\section{Microarray analysis and data capture}

Microarray studies were performed with an initial amount of $250 \mathrm{ng}$ total RNA as previously described [98]. All steps of cDNA synthesis, biotin labeling, fragmentation, hybridization, staining, washing and scanning were performed according to the manufacturer's recommendations (Affymetrix, Santa Clara, CA). The 
Affymetrix GeneChip Mouse 4302.0 was used for microarray analysis and was scanned using a GeneChip Scanner 3000 (Affymetrix). The microarray scanned image and intensity files (.cel file) were imported into the GenPlex gene expression analysis software (http:// genplex.co.kr). Data normalization was performed using MAS 5.0 and Global Median normalization. Differentially expressed genes were selected using a volcano plot based on $>1.5$-fold change using Welch's $t$-test $(P<0.05)$ and DEG filtering.

The microarray data were uploaded to the Gene Expression Omnibus (GEO) database [accession number GSE 75277].

\section{Quantitative real-time RT-PCR analysis}

The differentially expressed genes were validated by quantitative real-time RT-PCR. The primers were purchased from GenoTech (Daejeon, Korea). Total RNA $(2 \mu \mathrm{g})$ was reverse-transcribed with SuperScript II (Invitrogen, Carlsbad, CA) using an oligo-dT primer as described by the manufacturer. cDNA samples were stored at $-20^{\circ} \mathrm{C}$ until use. Quantitative real-time RT-PCR was performed in a $20 \mu \mathrm{l}$ reaction volume containing $0.5 \mu \mathrm{l}(10 \mathrm{pM})$ forward and reverse specific primers, $10 \mu 1$ of SYBR Green master mix (Applied Biosystems, Carlsbad, Califomia), $2 \mu 1$ of cDNA and $7 \mu 1$ of nucleasefree water. The cDNA was amplified using a StepOne and StepOnePlus Real-Time PCR System (Applied Biosystems) following the manufacturer's protocol. The $18 S$ ribosomal RNA primers were used as an internal control. Note, the primer sequences of all genes investigated are listed in Table S1.

\section{Western blot analysis}

Liver tissue from diclofenac $(30 \mathrm{mg} / \mathrm{kg})$ and salinetreated mice (day 1, 3 and 14) was removed, snap-frozen in liquid nitrogen and kept in a deep freezer until further processing. The frozen tissue together with $600 \mu \mathrm{l}$ of PRO-PREPTM solution (iNtRON, Seongnam, Korea) was homogenized with a TissueLyser (Qiagen, Hilden, Germany); the homogenate was incubated on ice for $30 \mathrm{~min}$ and centrifuged at $13,000 \mathrm{rpm}$ and $4^{\circ} \mathrm{C}$ for $5 \mathrm{~min}$. The supernatant was transferred to a new tube and the protein concentration was determined with the Bradford Protein Assay (Bio-Rad, Hercules, CA). Subsequently, the samples were heated with Bolt ${ }^{\mathrm{TM}}$ sampling buffer (Life technologies, Grand Island, NY) and reducing agent (Invitrogen, Waltham, MA) at $70^{\circ} \mathrm{C}$ for $10 \mathrm{~min}$. An equal amount of protein lysates was loaded to Bolt ${ }^{\mathrm{TM}}$ bio-tris plus mini gels (Life technologies, Grand Island, NY) and blotted onto a nitrocellulose membrane (Millipore, Bedford, MA). After protein transfer, membranes were blocked with Tris-buffered saline (TBS) $/ 0.1 \%$ Tween 20 (ScyTek, West Logan, UT) and 5\% $(\mathrm{w} / \mathrm{v})$ nonfat dry milk for $1 \mathrm{~h}$ at room temperature, and thereafter probed with the indicated primary antibodies (1:200 1:1000) overnight at $4^{\circ} \mathrm{C}$. All antibodies were diluted with SuperBlock T20 (PBS) blocking buffer (Thermo, Waltham, MA). After washing of the membranes these were incubated with horseradish peroxidase (HRP)conjugated secondary antibodies $(1: 2000)$ for $2 \mathrm{~h}$. Once again the membranes were washed to remove excess secondary antibody and bands were visualized using the enhanced chemiluminescence (ECL) detection system (Pierce Biotechnology, Rockford, IL) according to the manufacturer's recommendations. The anti-STAT3, antiphosphorus STAT3, anti-fibronectin, anti-M-CSF, antiRC-PTP, anti-actin antibodies and secondary antibody were purchased from Santa Cruz Biotechnology (Santa Cruz, CA). The anti-GHR was purchased from Abcam (Cambridge, UK).

List of antibodies used in the western blot:

\begin{tabular}{|l|l|l|l|}
\hline \multicolumn{1}{|c|}{ Antibody } & \multicolumn{1}{|c|}{ Vendor } & \multicolumn{1}{|c|}{ Cat no. } & $\begin{array}{c}\text { Lot } \\
\text { number }\end{array}$ \\
\hline $\begin{array}{l}\text { Growth } \\
\text { hormone } \\
\text { receptor }\end{array}$ & Abcam & ab134078 & $\begin{array}{l}\text { YI05181 } \\
\text { 0CS }\end{array}$ \\
\hline CTLA4 & Abcam & ab134090 & \\
\hline $\begin{array}{l}\text { Actin } \\
\text { (C-11) }\end{array}$ & $\begin{array}{l}\text { Santa Cruz } \\
\text { Biotechnology }\end{array}$ & sc-1615 & E0913 \\
\hline APCS & $\begin{array}{l}\text { Santa Cruz } \\
\text { Biotechnology }\end{array}$ & sc69796 & SAP(6E6) \\
\hline $\begin{array}{l}\text { Fibronectin } \\
\text { (EP5) }\end{array}$ & $\begin{array}{l}\text { Santa Cruz } \\
\text { Biotechnology }\end{array}$ & sc-8422 & G1812 \\
\hline $\begin{array}{l}\text { M-CSF } \\
\text { (D-4) }\end{array}$ & $\begin{array}{l}\text { Santa Cruz } \\
\text { Biotechnology }\end{array}$ & sc-365779 & A0912 \\
\hline $\begin{array}{l}\text { p-STAT3 } \\
\text { (B-7) }\end{array}$ & $\begin{array}{l}\text { Santa Cruz } \\
\text { Biotechnology }\end{array}$ & sc-8029 & J0813 \\
\hline $\begin{array}{l}\text { STAT3 } \\
\text { (C-20) }\end{array}$ & $\begin{array}{l}\text { Santa Cruz } \\
\text { Biotechnology }\end{array}$ & sc-482 & I1113 \\
\hline $\begin{array}{l}\text { TC-PTP } \\
\text { (S-17) }\end{array}$ & $\begin{array}{l}\text { Santa Cruz } \\
\text { Biotechnology }\end{array}$ & sc-102129 & \\
\hline CD44 & $\begin{array}{l}\text { R \& D SYS- } \\
\text { TEMS }\end{array}$ & AF6127 & \\
\hline
\end{tabular}

\section{Histopathology}

Using standard operating procedures of the laboratory a range of stains were employed to evaluate the liver morphology of control and diclofenac treated mice and included Hematoxylin and eosin (H \& E), Periodic acid-Schiff reaction (PAS), PAS diastase digestion, Elastica van Gieson, silver and Prussian blue.

\section{Immunohistochemistry}

Livers from control and diclofenac treated animals were fixed in $4 \%$ buffered paraformaldehyde and 
embedded in paraffin block using standard protocols of the laboratory. $1 \mu \mathrm{m}$ thick sections were deparaffinised and rehydrated through a descending alcohol series followed by a 4 min washing step in distilled H2O. Subsequently, antigen retrieval was performed in citrate buffer $(\mathrm{pH}$ 6) in a water bath at $98^{\circ} \mathrm{C}$ for $30 \mathrm{~min}$. The ZytoChemPlus HRP Polymer-Kit of Zytomed Systems, Germany was used for immunohistochemistry. The slides were rinsed with distilled $\mathrm{H} 2 \mathrm{O}$ and after a 5 min incubation step in tris-buffered saline (washing buffer), endogenous peroxidase activity was blocked with $3 \%$ peroxidase blocking reagent (Merck, Germany) for 5 min followed by a second washing step. Thereafter, the sections were blocked for 5 min with protein-block serum free reagent (ZytoChem-Plus HRP Polymer-Kit, reagent 1) and incubated with primary antibodies for $60 \mathrm{~min}$. The antibodies were purchased from diverse vendors and diluted with washing buffer as given in parenthesis: CD 31 (DAKO clone JC 70 A, Germany diluted to 1:75), CD68 (DAKO clone KP-1, Germany diluted to 1:100), Lipopolysacharide binding protein sc-14666 (Santa Cruz Biotechnology, Inc., USA diluted to 1: 25), Tc-PTP sc102192 (Santa Cruz Biotechnology, Inc., USA diluted to 1:75), macrophage colony stimulating factor sc-365779 (Santa Cruz Biotechnology, Inc., USA diluted to 1:300), Ki-67 (Thermo Fischer clone SP 6, Germany diluted to 1:100) fibronectin sc-8442 (Santa Cruz Biotechnology, Inc., USA diluted to 1:50), growth hormone receptor ab134087 (Abcam, UK diluted to 1:300), Leptin receptor sc-18931 (Santa Cruz Biotechnology, Inc., USA diluted to 1:50) and Hep Par1 clone OCH1E5 (Santa Cruz Biotechnology sc-58693, Inc., USA diluted to 1:800). The bound primary antibodies or bridging antibodies were incubated with labelled polymer HRP Anti-Rabbit or anti Mouse secondary antibody (ZytoChem-Plus HRP Polymer-Kit, reagent 2) for $20 \mathrm{~min}$. Subsequently, the reaction was developed and visualized by use of reagent 3 of the ZytoChem-Plus HRP Polymer-Kit and by placing the slides in a moist chamber at room temperature allowing an incubation time of $30 \mathrm{~min}$.

Finally, the sections were counterstained with Haematoxylin for $5 \mathrm{~min}$, washed under running warm tap water for $10 \mathrm{~min}$ and dehydrated in a cabinet at $60^{\circ} \mathrm{C}$ for $20 \mathrm{~min}$, coverslipped and examined under a light microscope (Nikon Ni-E microscope, Japan). Image capture and photo- documentation was done with the Nikon NIS basic research microscopic imaging software version 4.3.

The images were converted into Tiff files and unless otherwise stated the images were finalised in Adobe Photoshop version CS5. With the exception of Ki67 and Hep Par 1 all immunohistochemistry images are shown in the auto-colour function mode.

\section{Primary genomic data analysis}

Commonly expressed genes amongst different treatment groups were determined by employing a
Venn diagram analysis, and inflammatory, immune and stress response genes were sorted by biological process and gene ontology using the GenPlex software version 3.0. The functions and canonical pathways of the differentially expressed genes were subsequently interrogated using the Ingenuity Pathway Analysis (IPA) software version 9.0; (Ingenuity Systems, Redwood City, CA). This system is continuously updated with new scientific publications, review articles, text books and KEGG ligand information stored in the ingenuity system knowledge base. $P$-values $<0.05$ were considered as statistically significant and therefore non-random association. $P$-values were calculated using the righttailed Fisher exact test.

\section{Bioinformatic analysis}

The microarray expression data were normalized using the MAS5 algorithm available within the GeneXplain 3.0 platform (http://www.genexplain. com/). Then, differentially expressed genes (DEGs) were determined by applying a hypergeometric test to the normalised data sets with a cut-off $\geq \pm 1.5$ fold change and $p$-value $<0.01$. Genes satisfying these conditions were grouped as up- and down-regulated and a heat map for DEGs was created based on the averagelinkage hierarchical clustering with Euclidean distance (ArrayTrack software Version 3.5.0 [99]).

\section{Functional enrichment analysis}

DEGs were mapped to various ontologies, i.e. biological processes, cellular components, molecular functions, reactome pathways and transcription factor classification. For each ontological term respective $p$-values were calculated using the GeneXplain platform, Version 3.0.

\section{Gene regulatory network analysis}

Regulatory gene networks were constructed with an analysis tool of the GeneWays database [http://wiki. biouml.org/index.php/Geneways] available within the GeneXplain platform Version 3.0. A default cut-off score of 0.2 , a FDR $<0.05$ and a Z-score at 1.0 with a maximum radius of 4 steps upstream of an input gene set was set to identify statistically significant master regulatory genes. Note, the GeneWays tool is an integrated system used to automatically extract, analyse, visualize and integrate molecular pathway data from published peer reviewed articles and more than eight million abstracts [100].

\section{Transcription factor binding site analysis}

The TRANSFAC ${ }^{\circledR} 2013.2$ library of positional weight matrices and 'vertebrate_non_redundant minSUM' profile was used for an identification of 
transcription factor binding sites (TFBS) in promoters of up- and down-regulated genes (Yes-set). Specifically, promoters of DEGs were extracted using an automated procedure with respect to the transcriptional start site (TSS) and contained the TFIIB recognition element and the TATA-box at the 5'-end, an initiator region around the TSS and a downstream promoter element (DPE) at the 3 '-end [101]. The extracted promoters were interrogated for cis-regulatory binding sites with a length of -1000 to +100 base pairs relative to the TSS. Overrepresentation of transcription factor binding sites in promoters of differentially expressed genes were identified by comparing individual sites in promoters of DEG (=Yes-set) and non-regulated genes (= No-set) as previously described by Stegmaier et al., 2011 [102].

\section{Construction of composite modules}

A composite module is a particular combination of positional weight matrices (PWM) for different transcription factors and is based on an analysis of individual TFBS with a test for pairwise co-occurrences of binding sites. As described recently, the approach represents a variant of the F-MATCH algorithm for binding site pairs and quantifies overrepresentation of promoter sequences with sites of both PWMs in the foreground set using the Fisher test [102-104]. Specifically, DEGs implicated in the inflammation, immune and stress response were considered for composite module $(\mathrm{CM})$ construction, and the procedure is based on the primary multi-component fitness function as to ascertain co-occupancy of different transcription factors in promoters of regulated genes [102, 104]. The default filtering criteria of the GeneXplain platform was used and statistically significant composite modules were determined.

\section{Abbreviations}

NSAID-Nonsteroidal anti-inflammatory drug; DILI-Drug-induced liver injury; ALT - Alanine aminotransferase; AST-Serum aspartate aminotransferase; ALP - Alkaline phosphatase; TBIL-Total bilirubin; H \& E -Hematoxylin and eosin; PAS- Periodic acid-Schiff; LPS-Lipopolysaccharide; Th-17-T helper 17 cells; DEGsDifferentially expressed genes; IPA-Ingenuity Pathway Analysis; TFBS-Transcription factor binding sites; TSSTranscription start site; PWM-Position weight matrix; DPE-Downstream promoter element; CMs-Composite modules; PPI-Protein- protein interaction; ROS-Reactive oxygen species.

\section{GRANT SUPPORT}

This work was supported by the General Research Program (NRF-2012M3A9C7050138) from the Ministry of Science, ICT and Future Planning, Republic of Korea. We also gratefully acknowledge support from The Virtual Liver Network (grant 031 6154) of the German Federal Ministry of Education and Research (BMBF) to J.B.

\section{CONFLICTS OF INTEREST}

The authors have no competing interests to declare in relation to this manuscript.

\section{REFERENCES}

1. Banks AT, Zimmerman HJ, Ishak KG, Harter JG. Diclofenac-associated hepatotoxicity: analysis of 180 cases reported to the Food and Drug Administration as adverse reactions. Hepatology. 1995; 22:820-827.

2. Aithal GP. Hepatotoxicity related to antirheumatic drugs. Nat Rev Rheumatol. 2011; 7:139-150.

3. Kretz-Rommel A, Boelsterli UA. Diclofenac covalent protein binding is dependent on acyl glucuronide formation and is inversely related to P450-mediated acute cell injury in cultured rat hepatocytes. Toxicol Appl Pharmacol. 1993; 120:155-161.

4. Lagas JS, Sparidans RW, Wagenaar E, Beijnen JH, Schinkel AH. Hepatic clearance of reactive glucuronide metabolites of diclofenac in the mouse is dependent on multiple ATP-binding cassette efflux transporters. Mol Pharmacol. 2010; 77:687-694.

5. Gomez-Lechon MJ, Ponsoda X, O'Connor E, Donato T, Jover R, Castell JV. Diclofenac induces apoptosis in hepatocytes. Toxicol In vitro. 2003; 17:675-680.

6. Boelsterli UA, Lim PL. Mitochondrial abnormalities-a link to idiosyncratic drug hepatotoxicity?. Toxicol Appl Pharmacol. 2007; 220:92-107.

7. Siu WP, Pun PB, Latchoumycandane C, Boelsterli UA. Baxmediated mitochondrial outer membrane permeabilization (MOMP), distinct from the mitochondrial permeability transition, is a key mechanism in diclofenac-induced hepatocyte injury: Multiple protective roles of cyclosporin A. Toxicol Appl Pharmacol. 2008; 227:451-461.

8. Fredriksson L, Herpers B, Benedetti G, Matadin Q, Puigvert JC, de Bont H, Dragovic S, Vermeulen NP, Commandeur JN, Danen E, de Graauw M, van de Water B. Diclofenac inhibits tumor necrosis factor-alpha-induced nuclear factor-kappaB activation causing synergistic hepatocyte apoptosis. Hepatology. 2011; 53:2027-2041.

9. Deng X, Liguori MJ, Sparkenbaugh EM, Waring JF, Blomme EA, Ganey PE, Roth RA. Gene expression profiles in livers from diclofenac-treated rats reveal intestinal bacteria-dependent and -independent pathways associated with liver injury. J Pharmacol Exp Ther. 2008; 327:634-644.

10. Yano A, Higuchi S, Tsuneyama K, Fukami T, Nakajima M, Yokoi T. Involvement of immune-related factors in diclofenac-induced acute liver injury in mice. Toxicology. 2012; 293:107-114. 
11. Pachkoria K, Lucena MI, Crespo E, Ruiz-Cabello F, Lopez-Ortega S, Fernandez MA, Romero-Gomez M, Madrazo A, Duran JA, de Dios AM, Borraz Y, Navarro JM, Andrade RJ, et al. Analysis of IL-10, IL-4 and TNF-alpha polymorphisms in drug-induced liver injury (DILI) and its outcome. J Hepatol. 2008; 49:107-114.

12. Aithal GP, Ramsay L, Daly AK, Sonchit N, Leathart JB, Alexander G, Kenna JG, Caldwell J, Day CP. Hepatic adducts, circulating antibodies, and cytokine polymorphisms in patients with diclofenac hepatotoxicity. Hepatology. 2004; 39:1430-1440.

13. Scully LJ, Clarke D, Barr RJ. Diclofenac induced hepatitis. 3 cases with features of autoimmune chronic active hepatitis. Dig Dis Sci. 1993; 38:744-751.

14. Gulmez SE, Larrey D, Pageaux GP, Lignot S, Lassalle R, Jove J, Gatta A, McCormick PA, Metselaar HJ, Monteiro E, Thorburn D, Bernal W, Zouboulis-Vafiadis I, et al. Transplantation for acute liver failure in patients exposed to NSAIDs or paracetamol (acetaminophen): the multinational case-population SALT study. Drug Saf 2013; 36:135-144.

15. Bjornsson ES, Bergmann OM, Bjornsson HK, Kvaran RB, Olafsson S. Incidence, presentation, and outcomes in patients with drug-induced liver injury in the general population of Iceland. Gastroenterology. 2013; 144: 1419-25, 1425.e1-3; quiz e19-20.

16. Aithal GP. Hepatotoxicity related to antirheumatic drugs. Nat Rev Rheumatol. 2011; 7:139-150.

17. Gao B, Jeong WI, Tian Z. Liver: An organ with predominant innate immunity. Hepatology. 2008; 47:729-736.

18. Hammerich L, Heymann F, Tacke F. Role of IL-17 and Th17 cells in liver diseases. Clin.Dev.Immunol. 2011; 2011:345803.

19. Goyette J, Geczy CL. Inflammation-associated S100 proteins: new mechanisms that regulate function. Amino Acids. 2011; 41:821-842.

20. Saiman Y, Friedman SL. The role of chemokines in acute liver injury. Front Physiol. 2012; 3:213.

21. Sawa Y, Arima Y, Ogura H, Kitabayashi C, Jiang JJ, Fukushima T, Kamimura D, Hirano T, Murakami M. Hepatic interleukin-7 expression regulates $\mathrm{T}$ cell responses. Immunity. 2009; 30:447-457.

22. van Heel DA. Interleukin 15: its role in intestinal inflammation. Gut. 2006; 55:444-445.

23. Miller AM. Role of IL-33 in inflammation and disease. J Inflamm (Lond). 2011; 8:22-9255-8-22.

24. Liaskou E, Wilson DV, Oo YH. Innate immune cells in liver inflammation. Mediators Inflamm. 2012; 2012:949157.

25. Deng X, Luyendyk JP, Ganey PE, Roth RA. Inflammatory stress and idiosyncratic hepatotoxicity: hints from animal models. Pharmacol Rev. 2009; 61:262-282.
26. Bode JG, Albrecht U, Haussinger D, Heinrich PC, Schaper F. Hepatic acute phase proteins-regulation by IL-6- and IL1-type cytokines involving STAT3 and its crosstalk with NF-kappaB-dependent signaling. Eur J Cell Biol. 2012; 91:496-505.

27. Kong F, Guo X, Noel JG, Wells DA, Lovell GJ, Ogle CK. Thermal injury-induced increases of hepatocyte SOCS3 lead to decreases in STAT3. Shock. 2002; 18:374-379.

28. Pillemer BB, Xu H, Oriss TB, Qi Z, Ray A. Deficient SOCS3 expression in CD4+CD25+FoxP3+ regulatory $\mathrm{T}$ cells and SOCS3-mediated suppression of Treg function. Eur.J.Immunol. 2007; 37:2082-2089.

29. Hershey GK. IL-13 receptors and signaling pathways: an evolving web. J Allergy Clin Immunol. 2003; 111:677-90; quiz 691.

30. Akira S. Roles of STAT3 defined by tissue-specific gene targeting. Oncogene. 2000; 19:2607-2611.

31. Alonzi T, Maritano D, Gorgoni B, Rizzuto G, Libert C, Poli V. Essential role of STAT3 in the control of the acute-phase response as revealed by inducible gene inactivation [correction of activation] in the liver. Mol Cell Biol. 2001; 21:1621-1632.

32. He G, Karin M. NF-kappaB and STAT3 - key players in liver inflammation and cancer. Cell Res. 2011; 21:159-168.

33. Burgess-Beusse BL, Darlington GJ. C/EBPalpha is critical for the neonatal acute-phase response to inflammation. Mol Cell Biol. 1998; 18:7269-7277.

34. Fantuzzi G, Faggioni R. Leptin in the regulation of immunity, inflammation, and hematopoiesis. J Leukoc Biol. 2000; 68:437-446.

35. Cottrell EC, Mercer JG. Leptin receptors. Handb Exp Pharmacol. 2012; 3-21. doi:3-21.

36. Gove ME, Rhodes DH, Pini M, van Baal JW, Sennello JA, Fayad R, Cabay RJ, Myers MG, Jr, Fantuzzi G. Role of leptin receptor-induced STAT3 signaling in modulation of intestinal and hepatic inflammation in mice. J Leukoc Biol. 2009; 85:491-496.

37. Bjorbaek C, Uotani S, da Silva B, Flier JS. Divergent signaling capacities of the long and short isoforms of the leptin receptor. J Biol Chem. 1997; 272:32686-32695.

38. Torisu T, Sato N, Yoshiga D, Kobayashi T, Yoshioka T, Mori H, Iida M, Yoshimura A. The dual function of hepatic SOCS3 in insulin resistance in vivo. Genes Cells. 2007; 12:143-154.

39. Vijayakumar A, Wu Y, Sun H, Li X, Jeddy Z, Liu C, Schwartz GJ, Yakar S, LeRoith D. Targeted loss of GHR signaling in mouse skeletal muscle protects against high-fat diet-induced metabolic deterioration. Diabetes. 2012; 61:94-103. 
40. Corrick RM, Li L, Frank SJ, Messina JL. Hepatic growth hormone resistance after acute injury. Endocrinology. 2013; 154:1577-1588.

41. Bjorbaek C, Kahn BB. Leptin signaling in the central nervous system and the periphery. Recent Prog Horm Res. 2004; 59:305-331.

42. Van Sweringen HL, Sakai N, Tevar AD, Burns JM, Edwards MJ, Lentsch AB. CXC chemokine signaling in the liver: impact on repair and regeneration. Hepatology. 2011; 54:1445-1453.

43. Denson LA, Menon RK, Shaufl A, Bajwa HS, Williams CR, Karpen SJ. TNF-alpha downregulates murine hepatic growth hormone receptor expression by inhibiting Sp1 and Sp3 binding. J Clin Invest. 2001; 107:1451-1458.

44. Scharl M, Hruz P, McCole DF. Protein tyrosine phosphatase non-receptor Type 2 regulates IFN-gamma-induced cytokine signaling in THP-1 monocytes. Inflamm Bowel Dis. 2010; 16:2055-2064.

45. Ley $\mathrm{K}$. The role of selectins in inflammation and disease. Trends Mol Med. 2003; 9:263-268.

46. Roudkenar MH, Kuwahara Y, Baba T, Roushandeh AM, Ebishima S, Abe S, Ohkubo Y, Fukumoto M. Oxidative stress induced lipocalin 2 gene expression: addressing its expression under the harmful conditions. J Radiat Res. 2007; 48:39-44.

47. Borkham-Kamphorst E, Drews F, Weiskirchen R. Induction of lipocalin-2 expression in acute and chronic experimental liver injury moderated by pro-inflammatory cytokines interleukin-1 beta through nuclear factor-kappaB activation. Liver Int. 2011; 31:656-665.

48. Guo Y, Fan Y, Qiu J, Liu Y, Gao J, Guo F. Polymorphisms in CTLA4 influence incidence of drug-induced liver injury after renal transplantation in Chinese recipients. PLoS One. 2012; 7: e51723.

49. Miyake Y, Ikeda F, Takaki A, Nouso K, Yamamoto K. $+49 \mathrm{~A} / \mathrm{G}$ polymorphism of cytotoxic T-lymphocyte antigen 4 gene in type 1 autoimmune hepatitis and primary biliary cirrhosis: A meta-analysis. Hepatol Res. 2011; 41:151-159.

50. Gibson HM, Hedgcock CJ, Aufiero BM, Wilson AJ, Hafner MS, Tsokos GC, Wong HK. Induction of the CTLA-4 gene in human lymphocytes is dependent on NFAT binding the proximal promoter. J Immunol. 2007; 179:3831-3840.

51. Zhang $\mathrm{W}, \mathrm{Xu} \mathrm{W}$, Xiong S. Macrophage differentiation and polarization via phosphatidylinositol 3-kinase/Akt-ERK signaling pathway conferred by serum amyloid $\mathrm{P}$ component. J Immunol. 2011; 187:1764-1777.

52. Mortensen RF, Beisel K, Zeleznik NJ, Le PT. Acute-phase reactants of mice. II. Strain dependence of serum amyloid P-component (SAP) levels and response to inflammation. J Immunol. 1983; 130:885-889.

53. Zahedi K, Whitehead AS. Acute phase induction of mouse serum amyloid $\mathrm{P}$ component. Correlation with other parameters of inflammation. J Immunol. 1989; 143:2880-2886.
54. Chiu CC, Sheu JC, Chen CH, Lee CZ, Chiou LL, Chou SH, Huang GT, Lee HS. Global gene expression profiling reveals a key role of CD44 in hepatic oval-cell reaction after 2-AAF/CCl4 injury in rodents. Histochem. Cell Biol. 2009; 132:479-489.

55. Ponta H, Sherman L, Herrlich PA. CD44: from adhesion molecules to signalling regulators. Nat Rev Mol Cell Biol. 2003; 4:33-45.

56. McKallip RJ, Fisher M, Gunthert U, Szakal AK, Nagarkatti PS, Nagarkatti M. Role of CD44 and its v7 isoform in staphylococcal enterotoxin B-induced toxic shock: CD44 deficiency on hepatic mononuclear cells leads to reduced activation-induced apoptosis that results in increased liver damage. Infect Immun. 2005; 73:50-61.

57. Solis MA, Chen YH, Wong TY, Bittencourt VZ, Lin YC, Huang LL. Hyaluronan regulates cell behavior: a potential niche matrix for stem cells. Biochem Res Int. 2012; 2012:346972.

58. Kang HS, Liao G, DeGraff LM, Gerrish K, Bortner CD, Garantziotis S, Jetten AM. CD44 plays a critical role in regulating diet-induced adipose inflammation, hepatic steatosis, and insulin resistance. PLoS One. 2013; 8:e58417.

59. Griffin MD, Lutz W, Phan VA, Bachman LA, McKean DJ, Kumar R. Dendritic cell modulation by 1alpha,25 dihydroxyvitamin D3 and its analogs: a vitamin D receptordependent pathway that promotes a persistent state of immaturity in vitro and in vivo. Proc Natl Acad Sci USA. 2001; 98:6800-6805.

60. Barish GD, Downes M, Alaynick WA, Yu RT, Ocampo CB, Bookout AL, Mangelsdorf DJ, Evans RM. A Nuclear Receptor Atlas: macrophage activation. Mol Endocrinol. 2005; 19:2466-2477.

61. von Essen MR, Kongsbak M, Schjerling P, Olgaard K, Odum N, Geisler C. Vitamin D controls T cell antigen receptor signaling and activation of human $\mathrm{T}$ cells. Nat Immunol. 2010; 11:344-349.

62. Moran-Auth Y, Penna-Martinez M, Shoghi F, RamosLopez E, Badenhoop K. Vitamin D status and gene transcription in immune cells. J Steroid Biochem Mol Biol. 2013; 136:83-85.

63. Tiosano D, Wildbaum G, Gepstein V, Verbitsky O, Weisman Y, Karin N, Eztioni A. The role of vitamin D receptor in innate and adaptive immunity: a study in hereditary vitamin D-resistant rickets patients. J Clin Endocrinol Metab. 2013; 98:1685-1693.

64. Olliver M, Spelmink L, Hiew J, Meyer-Hoffert U, Henriques-Normark B, Bergman P. Immunomodulatory effects of vitamin D on innate and adaptive immune responses to Streptococcus pneumoniae. J Infect Dis. 2013; 208:1474-1481.

65. Ding N, Yu RT, Subramaniam N, Sherman MH, Wilson C, Rao R, Leblanc M, Coulter S, He M, Scott C, Lau SL, Atkins AR, Barish GD, et al. A vitamin D receptor/SMAD 
genomic circuit gates hepatic fibrotic response. Cell. 2013; 153:601-613.

66. Barchetta I, Carotti S, Labbadia G, Gentilucci UV, Muda AO, Angelico F, Silecchia G, Leonetti F, Fraioli A, Picardi A, Morini S, Cavallo MG. Liver vitamin D receptor, CYP2R1, and CYP27A1 expression: relationship with liver histology and vitamin D3 levels in patients with nonalcoholic steatohepatitis or hepatitis $\mathrm{C}$ virus. Hepatology. 2012; 56:2180-2187.

67. Baudy AR, Reeves EK, Damsker JM, Heier C, Garvin LM, Dillingham BC, McCall J, Rayavarapu S, Wang Z, Vandermeulen JH, Sali A, Jahnke V, Duguez S, et al. Delta-9,11 modification of glucocorticoids dissociates nuclear factor-kappaB inhibitory efficacy from glucocorticoid response element-associated side effects. J Pharmacol Exp Ther. 2012; 343:225-232.

68. Phuc Le P, Friedman JR, Schug J, Brestelli JE, Parker JB, Bochkis IM, Kaestner KH. Glucocorticoid receptor-dependent gene regulatory networks. PLoS Genet. 2005; 1:e16.

69. Medzhitov R, Horng T. Transcriptional control of the inflammatory response. Nat Rev Immunol. 2009; 9:692-703.

70. Grall F, Gu X, Tan L, Cho JY, Inan MS, Pettit AR, Thamrongsak U, Choy BK, Manning C, Akbarali Y, Zerbini L, Rudders S, Goldring SR, et al. Responses to the proinflammatory cytokines interleukin-1 and tumor necrosis factor alpha in cells derived from rheumatoid synovium and other joint tissues involve nuclear factor kappaB-mediated induction of the Ets transcription factor ESE-1. Arthritis Rheum. 2003; 48:1249-1260.

71. Nei $\mathrm{Y}$, Obata-Ninomiya $\mathrm{K}$, Tsutsui $\mathrm{H}$, Ishiwata $\mathrm{K}$, Miyasaka M, Matsumoto K, Nakae S, Kanuka H, Inase N, Karasuyama H. GATA-1 regulates the generation and function of basophils. Proc Natl Acad Sci USA. 2013; 110:18620-18625.

72. Mwinyi J, Nekvindova J, Cavaco I, Hofmann Y, Pedersen RS, Landman E, Mkrtchian S, Ingelman-Sundberg M. New insights into the regulation of CYP2C9 gene expression: the role of the transcription factor GATA-4. Drug Metab Dispos. 2010; 38:415-421.

73. Tong Q, Tsai J, Tan G, Dalgin G, Hotamisligil GS. Interaction between GATA and the C/EBP family of transcription factors is critical in GATA-mediated suppression of adipocyte differentiation. Mol Cell Biol. 2005; 25:706-715.

74. Schrem H, Klempnauer J, Borlak J. Liver-enriched transcription factors in liver function and development. Part I: the hepatocyte nuclear factor network and liver-specific gene expression. Pharmacol Rev. 2002; 54:129-158.

75. Armendariz AD, Krauss RM. Hepatic nuclear factor 1-alpha: inflammation, genetics, and atherosclerosis. Curr. Opin.Lipidol. 2009; 20:106-111.

76. Babeu JP, Boudreau F. Hepatocyte nuclear factor 4-alpha involvement in liver and intestinal inflammatory networks. World J Gastroenterol. 2014; 20:22-30.
77. Schrem H, Klempnauer J, Borlak J. Liver-enriched transcription factors in liver function and development. Part II: the C/EBPs and D site-binding protein in cell cycle control, carcinogenesis, circadian gene regulation, liver regeneration, apoptosis, and liver-specific gene regulation. Pharmacol Rev. 2004; 56:291-330.

78. Sahini N, Borlak J. Recent insights into the molecular pathophysiology of lipid droplet formation in hepatocytes. Prog Lipid Res. 2014; 54:86-112.

79. Fridman JS, Lowe SW. Control of apoptosis by p53. Oncogene. 2003; 22:9030-9040.

80. Levrero M, De Laurenzi V, Costanzo A, Gong J, Wang JY, Melino G. The p53/p63/p73 family of transcription factors: overlapping and distinct functions. J Cell Sci. 2000; 113:1661-1670.

81. Jo Y, Oh JH, Yoon S, Bae H, Hong MC, Shin MK, Kim YS. The comparative analysis of in vivo and in vitro transcriptome data based on systems biology. Bio Chip Journal. 2012; 6:290-302.

82. Rosen ED, Hsu CH, Wang X, Sakai S, Freeman MW, Gonzalez FJ, Spiegelman BM. C/EBPalpha induces adipogenesis through PPARgamma: a unified pathway. Genes Dev. 2002; 16:22-26.

83. Glass CK, Ogawa S. Combinatorial roles of nuclear receptors in inflammation and immunity. Nat Rev Immunol. 2006; 6:44-55.

84. Glass CK, Saijo K. Nuclear receptor transrepression pathways that regulate inflammation in macrophages and $\mathrm{T}$ cells. Nat Rev Immunol. 2010; 10:365-376.

85. Schroeder T, Just U. Notch signalling via RBP-J promotes myeloid differentiation. EMBO J. 2000; 19:2558-2568.

86. Xu H, Zhu J, Smith S, Foldi J, Zhao B, Chung AY, Outtz H, Kitajewski J, Shi C, Weber S, Saftig P, Li Y, Ozato K, et al. Notch-RBP-J signaling regulates the transcription factor IRF8 to promote inflammatory macrophage polarization. Nat Immunol. 2012; 13:642-650.

87. Zollner G, Trauner M. Nuclear receptors as therapeutic targets in cholestatic liver diseases. Br J Pharmacol. 2009; 156:7-27.

88. Kim MS, Shigenaga J, Moser A, Feingold K, Grunfeld C. Repression of farnesoid $\mathrm{X}$ receptor during the acute phase response. J Biol Chem. 2003; 278:8988-8995.

89. Jiang T, Wang XX, Scherzer P, Wilson P, Tallman J, Takahashi H, Li J, Iwahashi M, Sutherland E, Arend L, Levi M. Farnesoid X receptor modulates renal lipid metabolism, fibrosis, and diabetic nephropathy. Diabetes. 2007; 56:2485-2493.

90. Ma WL, Lai HC, Yeh S, Cai X, Chang C. Androgen receptor roles in hepatocellular carcinoma, fatty liver, cirrhosis and hepatitis. Endocr Relat Cancer. 2014; 21:R165-82.

91. Ma WL, Hsu CL, Wu MH, Wu CT, Wu CC, Lai JJ, Jou YS, Chen $\mathrm{CW}$, Yeh $\mathrm{S}$, Chang C. Androgen receptor is a new potential therapeutic target for the treatment of 
hepatocellular carcinoma. Gastroenterology. 2008; 135:947-55, 955.e1-5.

92. Feng H, Cheng AS, Tsang DP, Li MS, Go MY, Cheung YS, Zhao GJ, Ng SS, Lin MC, Yu J, Lai PB, To KF, Sung JJ. Cell cycle-related kinase is a direct androgen receptorregulated gene that drives beta-catenin/ $\mathrm{T}$ cell factordependent hepatocarcinogenesis. J Clin Invest. 2011; 121:3159-3175.

93. Koch A, Steffen J, Kruger E. TCF11 at the crossroads of oxidative stress and the ubiquitin proteasome system. Cell Cycle. 2011; 10:1200-1207.

94. Huan C, Kelly ML, Steele R, Shapira I, Gottesman SR, Roman CA. Transcription factors TFE3 and TFEB are critical for CD40 ligand expression and thymus-dependent humoral immunity. Nat Immunol. 2006; 7:1082-1091.

95. Nakagawa Y, Shimano H, Yoshikawa T, Ide T, Tamura M, Furusawa $M$, Yamamoto $T$, Inoue $\mathrm{N}$, Matsuzaka $\mathrm{T}$, Takahashi A, Hasty AH, Suzuki H, Sone H, et al. TFE3 transcriptionally activates hepatic IRS-2, participates in insulin signaling and ameliorates diabetes. Nat Med. 2006; 12:107-113.

96. Borlak J, Chougule A, Singh PK. How useful are clinical liver function tests in in vitro human hepatotoxicity assays? Toxicol In vitro. 2014; 28:784-795.

97. Anderson N, Meier T, Borlak J. Toxicogenomics applied to cultures of human hepatocytes enabled an identification of novel petasites hybridus extracts for the treatment of migraine with improved hepatobiliary safety. Toxicol Sci 2009; 112:507-520.
98. Londhe KB, Borlak J. A cross-platform comparison of genome-wide expression changes of laser microdissected lung tissue of C-Raf transgenic mice using 3'IVT and exon array. PLoS One. 2012; 7:e40778.

99. Xu J, Kelly R, Fang H, Tong W. ArrayTrack: a free FDA bioinformatics tool to support emerging biomedical research-an update. Hum Genomics. 2010; 4:428-434.

100. Rzhetsky A, Iossifov I, Koike T, Krauthammer M, Kra P, Morris M, Yu H, Duboue PA, Weng W, Wilbur WJ, Hatzivassiloglou V, Friedman C. GeneWays: a system for extracting, analyzing, visualizing, and integrating molecular pathway data. J Biomed Inform. 2004; 37:43-53.

101. Smale ST, Kadonaga JT. The RNA polymerase II core promoter. Annu Rev Biochem. 2003; 72:449-479.

102. Stegmaier P, Voss N, Meier T, Kel A, Wingender E, Borlak J. Advanced computational biology methods identify molecular switches for malignancy in an EGF mouse model of liver cancer. PLoS One. 2011; 6:e17738.

103. Kel A, Reymann S, Matys V, Nettesheim P, Wingender E, Borlak J. A novel computational approach for the prediction of networked transcription factors of aryl hydrocarbon-receptorregulated genes. Mol Pharmacol. 2004; 66:1557-1572.

104. Kel A, Konovalova T, Waleev T, Cheremushkin E, KelMargoulis O, Wingender E. Composite Module Analyst: a fitness-based tool for identification of transcription factor binding site combinations. Bioinformatics. 2006; 22:1190-1197. 